\title{
An Intercomparison of GCM and RCM Dynamical Downscaling for Characterizing the Hydroclimatology of California and Nevada
}

\author{
ZeXuan Xu AND Alan M. RhoAdes \\ Climate and Ecosystem Sciences Division, Lawrence Berkeley National Laboratory, Berkeley, California \\ HANS JOHANSEN \\ Computational Research Division, Lawrence Berkeley National Laboratory, Berkeley, California \\ PAUl A. UlLRich \\ Department of Land, Air and Water Resources, University of California, Davis, Davis, California \\ WiLliam D. COLLINS \\ Climate and Ecosystem Sciences Division, Lawrence Berkeley National Laboratory, and Department of Earth and \\ Planetary Science, University of California, Berkeley, Berkeley, California
}

(Manuscript received 20 September 2017, in final form 24 July 2018)

\begin{abstract}
Dynamical downscaling is a widely used technique to properly capture regional surface heterogeneities that shape the local hydroclimatology. However, in the context of dynamical downscaling, the impacts on simulation fidelity have not been comprehensively evaluated across many user-specified factors, including the refinements of model horizontal resolution, large-scale forcing datasets, and dynamical cores. Two global-toregional downscaling methods are used to assess these: specifically, the variable-resolution Community Earth System Model (VR-CESM) and the Weather Research and Forecasting (WRF) Model with horizontal resolutions of 28,14 , and $7 \mathrm{~km}$. The modeling strategies are assessed by comparing the VR-CESM and WRF simulations with consistent physical parameterizations and grid domains. Two groups of WRF Models are driven by either the NCEP reanalysis dataset (WRF_NCEP) or VR-CESM7 results (WRF_VRCESM) to evaluate the effects of large-scale forcing datasets. The simulated hydroclimatologies are compared with reference datasets for key properties including total precipitation, snow cover, snow water equivalent (SWE), and surface temperature. The large-scale forcing datasets are critical to the WRF simulations of total precipitation but not surface temperature, controlled by the wind field and atmospheric moisture transport at the ocean boundary. No significant benefit is found in the regional average simulated hydroclimatology by increasing horizontal resolution refinement from 28 to $7 \mathrm{~km}$, probably due to the systematic biases from the diagnostic treatment of rainfall and snowfall in the microphysics scheme. The choice of dynamical core has little impact on total precipitation but significantly determines simulated surface temperature, which is affected by the snow-albedo feedback in winter and soil moisture estimations in summer.
\end{abstract}

\section{Introduction}

Global climate models (GCMs) are virtual laboratories used to understand the processes that shape Earth's climatology. At present, most GCM simulations are still performed at relatively coarse horizontal resolutions $\left(\sim 1^{\circ}\right)$ due to the tremendous increase in computational cost required at finer resolutions. Therefore, modeling

Corresponding author: Zexuan Xu, zexuanxu@lbl.gov hydroclimatological characteristics, especially in mountain regions, at these coarser GCM resolutions is problematic as orographic features are heavily smoothed and inaccurately represented. The complex geographic characteristics of California, including the Central Valley and the Sierra Nevada mountain range, necessitate finerresolution climate simulations that can resolve important details in topography and land use coverage (Chin 2008; Pierce et al. 2013a; Huang et al. 2016). The Sierra Nevada is particularly important to represent in climate 
simulations as it acts as a natural dam to the dominant pathway of atmospheric moisture transport and a natural reservoir that provides $72 \%$ additional storage for irrigation and municipal use during seasonally dry summers (Dettinger and Anderson 2015). Another unresolved feature at conventional GCM resolutions is the variability of land use and land cover in the California Central Valley. This region is one of the most important croplands in the continental United States, providing $50 \%$ of the fruits, nuts, and vegetables of the United States, and is watered primarily by snowmelt-fed rivers from the Sierra Nevada (Wilkinson et al. 2002).

In addition to resolving the Sierra Nevada mountain range and Central Valley, the accurate representation of California's Mediterranean climate, characterized by cold, wet winters and warm, dry summers, is critical. California receives one-half of its total annual precipitation during the winter months from December to February (DJF; California Data Exchange Center 2016), of which two-thirds precipitates in the northern and mountainous parts of California (Wise 2012). Importantly, this precipitation is received in 5-15 days per year through a few atmospheric river events (Dettinger et al. 2011), making its precipitation patterns some of the most intermittent in the United States. On the other hand, summertime temperatures and extreme heat events are a common feature in California and play an important role in determining agricultural output and the longevity of the state's water supply. These events will likely play an increased role by the end of the century in reducing forest coverage and snowpack in the Sierra Nevada, and the magnitude of impact will be determined by the emission scenario that comes to fruition (Hayhoe et al. 2004). Future projections also show the tendency for warmer and more persistent dry summer months, which will increase wildfire probability and increase the number of extreme heat events in the Central Valley (Lenihan et al. 2003). Without action, this will impact the state's electricity deficits associated with residential cooling and groundwater pumping (Miller et al. 2008). Thus, in order to accurately represent California's hydroclimatology, climate simulations must skillfully represent wintertime precipitation, the storage of this precipitation as mountain snowpack, and summertime heat, especially with the onset of anthropogenic climate change (Rhoades et al. 2018a).

To provide usable and accurate climate information that properly projects impacts on agriculture and water supplies, dynamical downscaling has been used to simulate the drivers of regional heterogeneity in both atmospheric and land processes (Hay and Clark 2003; Qian et al. 2009; Gutzler and Robbins 2011; Pierce et al. 2013b). Over recent decades, several regional climate models (RCMs) have emerged (Giorgi and Gutowski 2015). The efficacy of these RCMs in representing the historical climate have been assessed in many research projects such as the Coordinated Regional Downscaling Experiment (CORDEX; Gutowski et al. 2016; Giorgi et al. 2009), the Prediction of Regional Scenarios and Uncertainties for Defining European Climate Change Risks and Effects (PRUDENCE; Christensen et al. 2007), the Ensembles-Based Predictions of Climate Changes and Their Impacts (ENSEMBLES) project (Van der Linden and Mitchell 2009), and the North American Regional Climate Change Assessment Program (NARCCAP; Mearns et al. 2009). These projects have helped to elucidate the common strengths and weaknesses of RCMs in simulating regional hydroclimate throughout the world. Some of the hydroclimate-related biases include a systematic warm and dry bias in many regions during summer (Caldwell et al. 2009), lack of irrigation processes (Huang and Ullrich 2016), and an overestimation of mountain precipitation in the Alps (Frei et al. 2003), the Andes (Urrutia and Vuille 2009), and the western United States (Caldwell et al. 2009). These biases may be explained by uncertainties in convective schemes (Caldwell et al. 2009; Subin et al. 2011) due to simplified physical processes (Boberg and Christensen 2012), lack of realistic sea surface temperature variability (Katragkou et al. 2015), the cascading effect of temperature bias on other hydroclimate variables (Christensen et al. 2008), and/or the size and location of the RCM domain (Heikkilä et al. 2011).

Within traditional dynamical downscaling options, the Weather Research and Forecasting (WRF) Model is one of the most widely used to simulate historical climate and to project future climate change in California and the greater western United States (Cayan et al. 2008; Caldwell et al. 2009; Leung and Qian 2009; Qian et al. 2009, 2010; Pavelsky et al. 2011; Subin et al. 2011; Pavelsky et al. 2012; Liou et al. 2013; Liu et al. 2017; Sun et al. 2016). Caldwell et al. (2009) evaluated WRF over California and concluded that an overprecipitation bias in winter and warmer temperature bias in summer was found, likely due to the convection scheme and the underprediction of soil moisture. Qian et al. (2010) and Pavelsky et al. (2011) identified that spatial resolution, especially in regions of complex terrain, were key in how well WRF represented precipitation and snowpack amounts in the western United States. Liu et al. (2017) corroborated these findings with extremely high-resolution simulations $(4 \mathrm{~km})$ and further highlighted the importance of proper boundary forcings at the edge of the RCM domains.

In addition to traditional RCM dynamical downscaling, variable-resolution GCMs (VRGCMs) have emerged as a 
promising technique for modeling regional hydroclimate. Unlike RCM dynamical downscaling, VRGCMs are a single unified model that can telescope resolution wherever desired. VRGCMs beneficially eliminate multimodel coupling which reduces the cascade of biases, alleviates simulation bottlenecks, and unifies the regional and global climate model communities; however, uncertainties surrounding scale-aware subgrid-scale parameterizations need to be evaluated. The GCMs that support variableresolution capabilities include the Geophysical Fluid Dynamics Laboratory finite-volume dynamical core on the cubed sphere (FV3; Harris and Lin 2013), the Model for Prediction Across Scales (MPAS; Heinzeller et al. 2016), and the Community Earth System Model (CESM; Collins et al. 2006; Hurrell et al. 2013; Zarzycki et al. 2014a,b, 2015). The variable-resolution option in CESM (VR-CESM) has demonstrated good performance in modeling the climate of California, and the greater western United States, when compared with reanalysis, observation, and RCM datasets (Rhoades et al. 2016; Huang et al. 2016; Huang and Ullrich 2016; Rhoades et al. 2018a; Huang and Ullrich 2017; Wu et al. 2017; Wang and Ullrich 2018; Gettelman et al. 2018; Wang et al. 2018a,b). Key hydroclimate biases have been identified in VR-CESM as shown in Huang et al. (2016), who found that summer temperature and winter precipitation were overestimated, and Rhoades et al. (2016) found too early of a peak snowpack timing and too fast of a melt rate.

The major research objective of this paper is to identify the hydroclimatological implications of three important factors in dynamical downscaling, including boundary forcing (reanalysis versus global climate model), horizontal resolution $(28,14$, and $7 \mathrm{~km})$, and dynamical core choice (hydrostatic versus nonhydrostatic). This study aims to advance our understanding of the sensitivities of these key factors in shaping VRGCM and RCM performance over California. The differences in hydroclimate simulations are assessed to gain insights into the drivers of structural uncertainty in Earth system modeling systems, given the considerable time and effort currently being committed to the development of dynamical downscaling techniques.

To address this objective, we utilize VR-CESM and WRF models, separately and together, to compare how well they represent the major hydroclimate variables that shape California's water supply. A group of WRF simulations forced by both National Centers for Environmental Prediction (NCEP) reanalysis and VR-CESM simulations are assessed and also compared to some of the VR-CESM results in Rhoades et al. (2018b). The WRF and VR-CESM models are set up with consistent model configurations (i.e., grid domains, land surface model, and subgrid-scale parameterizations). Section 2 introduces the observational and reanalysis datasets used for historical intercomparison and the setup of the WRF Model and VR-CESM. Section 3 compares the simulation results of WRF driven by two forcing datasets, discusses the differences between VR-CESM and the WRF Model, and analyzes the implications of horizontal resolution refinement. Section 4 highlights the implications of boundary forcing, horizontal resolution, and dynamical core choice in shaping the simulated hydroclimatologies of the two different downscaling methods.

\section{Experimental setup}

\section{a. Variable-resolution CESM}

A more thorough description of the VR-CESM simulations evaluated in this study can be found in Rhoades et al. (2018b) and is only briefly introduced here. The variable-resolution cubed-sphere grids are generated by SQuadGen (Ullrich 2014) for use in the Community Atmospheric Model version 5 with the Spectral Element dynamical core (CAM5-SE) and the Community Land Model version 4.0 with Satellite Phenology (CLM4-SP). A quasi-uniform $111-\mathrm{km}\left(1.00^{\circ}\right)$ base resolution is utilized globally. The variable-resolution grid is gradually refined to $55 \mathrm{~km}\left(0.5^{\circ}\right), 28 \mathrm{~km}\left(0.25^{\circ}\right)$, and $14 \mathrm{~km}\left(0.125^{\circ}\right)$ focused over California. The CESM configuration is based on the well-established Atmosphere Model Intercomparison Project (AMIP) protocols, namely, compset FAMIPC5, with full atmospheric-land coupling and prescribed sea ice and sea surface temperature observations at monthly intervals. The monthly prescribed sea ice and sea surface temperatures are derived from the HadISST1 and NOAA OI datasets (Hurrell et al. 2008). The VR-CESM topography is generated using a resolution-dependent smoothing of a global 30 arc-s $(\sim 1 \mathrm{~km})$ elevation USGS dataset (GTOPO30) using established methods highlighted in Zarzycki et al. (2015). To maximize the utility of model horizontal resolution, the highest-resolution surface cover datasets were used for CLM4-SP. These datasets represent observed land surface cover characteristics (e.g., forest and soil cover) for year 2000 at approximately $5 \mathrm{~km}$ resolution. To ensure consistent comparison between VR-CESM and the WRF simulations, this study only utilized CESM version 1.2.2 simulations from Rhoades et al. (2018b) with the MG1 microphysics scheme (Morrison and Gettelman 2008).

\section{b. WRF Model}

The WRF Model (Skamarock et al. 2005) features multiple options for boundary layer, convection, microphysics, and radiation as well as several land 

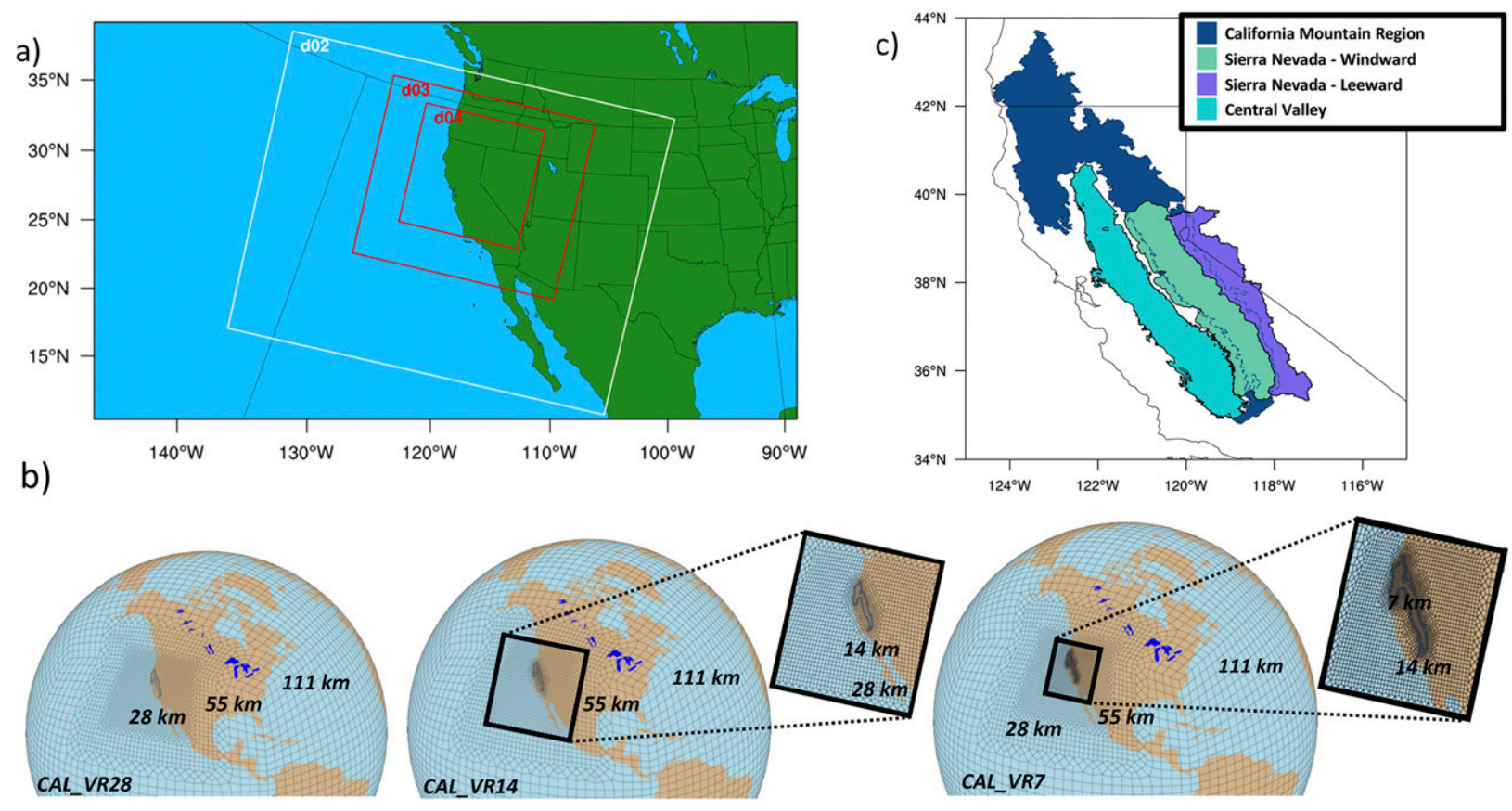

FIG. 1. (a) The WRF nested domains shown at $28 \mathrm{~km}\left(0.25^{\circ}\right), 14 \mathrm{~km}\left(0.125^{\circ}\right)$ and $7 \mathrm{~km}\left(0.0625^{\circ}\right)$. (b) The set of VR-CESM grids with a quasi-uniform $111-\mathrm{km}\left(1.00^{\circ}\right)$ base resolution and refinement focused over California's mountainous regions at $55 \mathrm{~km}\left(0.5^{\circ}\right), 28 \mathrm{~km}$ $\left(0.25^{\circ}\right)$, and $14 \mathrm{~km}\left(0.125^{\circ}\right)$. (c) The evaluation regions used in this study for the California Mountain Region, Sierra Nevada windward and leeward, and Central Valley. The California Mountain Region is highlighted in dark blue and via a dashed dark blue line when overlapping with the other regions.

surface model choices. In this study, the recent Advanced Research version of WRF (WRF-ARW), version 3.8, modeling system is used, with fully compressible, nonhydrostatic equations solved in the dynamical core. WRF simulations are set up with two groups of initial and boundary conditions. One is driven by the 6-hourly NCEP Global Forecasting System (GFS) analyses on a $1^{\circ}$ grid with 27 hydroclimate variables (NCEP 2000) at the lateral boundaries of the WRF outer domain, abbreviated as WRF_NCEP in this paper. The other group of WRF simulations is abbreviated as WRF_VRCESM and employs the intermediate files generated from the 6-hourly VR-CESM outputs, which include the variables zonal wind $U$, meridional wind $V$, specific humidity $Q$, temperature $T$, and surface pressure (PS) in CAM5-SE, and snow water equivalent (SWE), surface temperature, soil temperature, and soil water content in CLM4-SP. There are five WRF simulations driven by VR-CESM results. The 7-km VR-CESM result is used as initial and boundary conditions for three WRF-VRCESM simulations at resolutions of 28,14 , and $7 \mathrm{~km}$, hereafter named WRF28_VRCESM7, WRF14_VRCESM7, and WRF7_VRCESM7. The other two WRF_VRCESM simulations are forced by the other VR-CESM simulations from Rhoades et al. (2018b) (i.e., 28 and $14 \mathrm{~km}$ ), now named WRF28_VRCESM28 and WRF14_VRCESM14.
Unlike the typical refinement ratio of 3:1 in the WRF nested domains, this study uses the refinement ratio of 2:1 for the purpose of a consistent comparison with the VR-CESM simulations. The nested domains and grid discretization are set up to be equivalent to those for the VR-CESM simulations, in which the three sets of grid refinement are centered on California for resolutions of 28,14 , and $7 \mathrm{~km}$ with two, three, and four nested domains, respectively. In all WRF simulations, the outermost domain has $99 \times 89$ grid points with $55-\mathrm{km}$ resolution, and its daughter nested domain has $128 \times 100$ grid points with $28-\mathrm{km}$ resolution. The third nested domain has $136 \times 120$ grid points within the 14-km-resolution simulation, and the innermost nested domain has $160 \times 160$ grid points within the $7-\mathrm{km}$ resolution simulation (Fig. 1). Ten grid points are used for relaxation to the coarse solution in each domain; grid nudging is not used in this study. Figure 2 highlights the difference in surface topography mean and variability against Parameter-Elevation Regressions on Independent Slopes Model (PRISM) decreases significantly with refinement in horizontal resolution divided by 2 . The 30 -arc-s $(\sim 1 \mathrm{~km})$ resolution USGSbased land use and land cover (LULC) datasets from Rhoades et al. (2018b) are also interpolated in the WRF simulation (Fig. 2). 

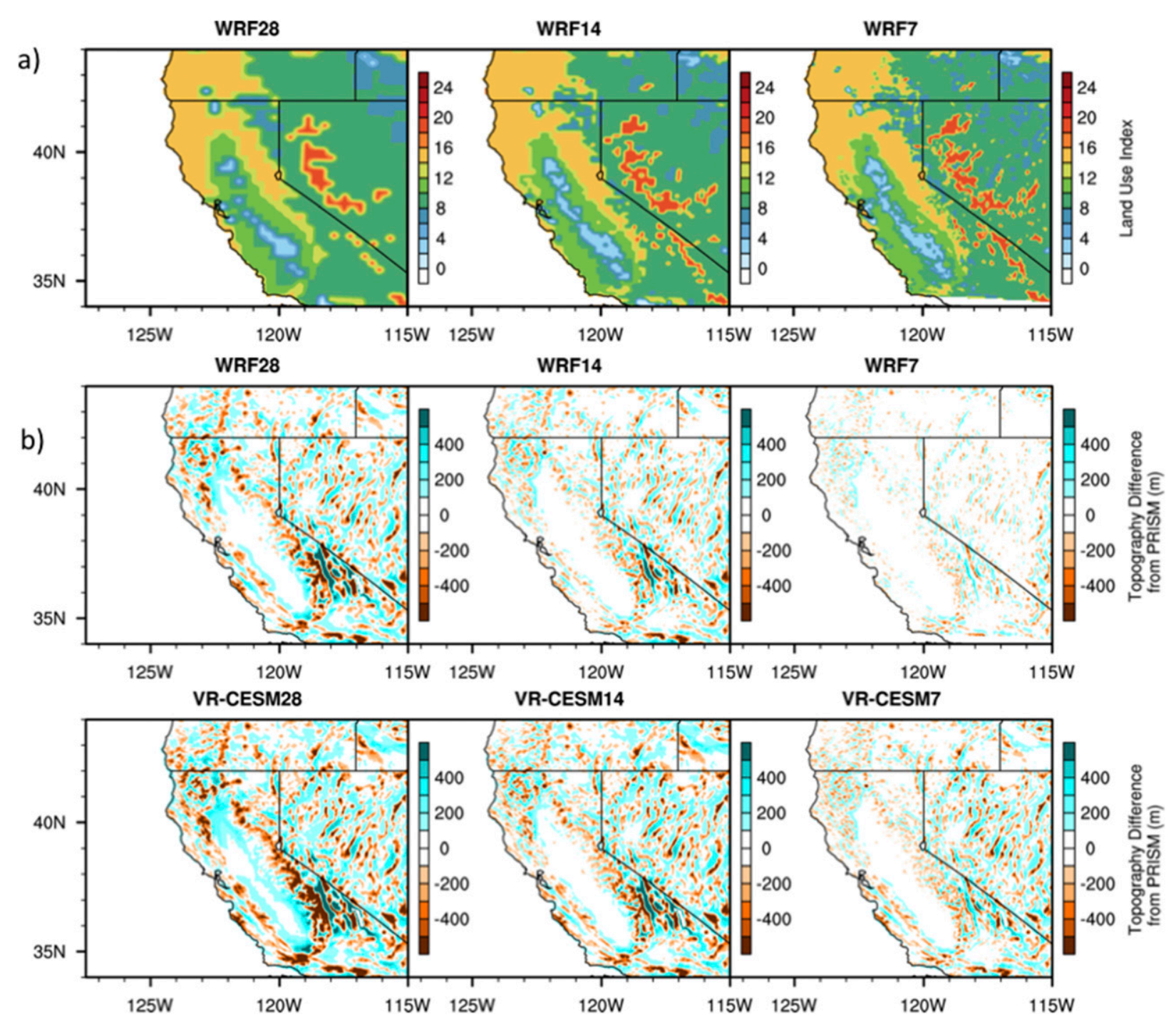

FIG. 2. (a) The land use index in WRF simulations at resolutions of $28 \mathrm{~km}\left(0.25^{\circ}\right), 14 \mathrm{~km}\left(0.125^{\circ}\right)$, and $7 \mathrm{~km}\left(0.0625^{\circ}\right)$. (b) The topographical difference between models and the USGS GTOPO 30-arc-s topography dataset across horizontal resolutions.

The WRF parameterizations and physics schemes can be found in Table 1. Generally, the physical parameterizations of WRF simulations are chosen to be consistent with the VR-CESM simulations for comparison. The two groups of WRF simulations use the CAM5.1 two-moment 5-class atmospheric microphysics scheme, which is the same approach used in the VR-CESM MG1 simulations in Rhoades et al. (2018b). To ensure a consistent comparison between the two downscaling methods, the CLM4-SP land surface model is chosen instead of the common options in WRF, such as Noah or Noah-MP. This is justified as CLM4-SP is the most advanced atmosphere-land coupling scheme available in WRF (Jin and Wen 2012) due to the availability of dynamic vegetation, higher-resolution soil, and a more comprehensive snowpack model. The CAM5-SE atmospheric microphysics schemes and the CLM4-SP land surface model are not default or commonly used in most WRF applications because of the additional computational cost. The MM5 similarity scheme is used for surface layer, and the University of Washington (UW) scheme is used for the planetary boundary layer. The Rapid Radiative Transfer Model for global climate models (RRTMG) longwave and shortwave radiation schemes, ZhangMcFarlane cumulus parameterization, and the UW shallow convection option from the CESM model with momentum transport are applied in the WRF simulations.

All WRF simulations were analyzed over the same periods as the VR-CESM simulations in Rhoades et al. (2018b), starting from 1 October 1999 to 1 March 2015, 
TABLE 1. WRF and VR-CESM parameterizations and physics schemes.

\begin{tabular}{lc}
\hline \hline \multicolumn{1}{c}{ Physics schemes } & \multicolumn{1}{c}{ WRF and VR-CESM } \\
\hline Microphysics & $\begin{array}{c}\text { CAM V5.1 two-moment 5-class } \\
\text { (Neale et al. 2010) }\end{array}$ \\
$\begin{array}{l}\text { Longwave radiation } \\
\text { Rhortwave radiation }\end{array}$ & RRTMG (Iacono et al. 2008) \\
Surface layer & Revised MM5 similarity theory \\
& (Jiménez et al. 2012) \\
Land surface model & CLM4 (Oleson et al. 2010) \\
Planetary boundary layer & UW (Bretherton and Park 2009) \\
Cumulus parameterization & Zhang and McFarlane (Zhang and \\
& McFarlane 1995) \\
Shallow convection option & UW (Bretherton and Park 2009) \\
\hline
\end{tabular}

with 16 DJF periods in winter and 15 June-August (JJA) periods in summer. DJF was selected as the study period as it accounts for $50 \%$ of the annual total precipitation (California Data Exchange Center 2016) and minimizes errors associated with snow-related feedbacks in the beginning of the accumulation period and at the end of the ablation period (Raleigh et al. 2013). Unlike VR-CESM, which features excellent parallel scalability, the largest number of processors that can be used in a WRF simulation is limited. Because of computational limitations, the WRF Model runs at $7 \mathrm{~km}$ resolution are divided up into 15 annual simulations, each starting from the beginning of each calendar year and terminating at the end of February of the next year. The 14- and 28-kmresolution WRF simulations are conducted with a similar approach, but are divided into three runs, each with 5-yr simulations starting from 1 October 1999, 1 January 2005, and 1 January 2010 to the end of February 2005, 2010, and 2015, respectively. All WRF simulations start with the initial conditions of either the NCEP reanalysis dataset or VR-CESM simulations at the starting date. As a consequence, the first two months of each WRF simulation are discarded as a spinup period to ensure convergence in the soil moisture and surface hydrology characteristics.

\section{c. Historical reference datasets}

The spatial and temporal resolutions for the VR-CESM, WRF_NCEP, and WRF_VRCESM simulations, as well as the observational and reanalysis datasets used as historical reference in this study, are presented in Table 2. These datasets were chosen based on their ability to characterize specific hydroclimate variables over large spatial areas of interest in this study. The variables derived from the datasets include total precipitation, snow cover, SWE, and surface temperature. The simulation outputs and historical reference datasets are compiled into a daily climate average, DJF/JJA seasonal average, and DJF/JJA climatological average over 1999-2015.

The PRISM dataset uses over 10000 quality-controlled observational station datasets along with a climate-elevation regression for each digital elevation model (DEM) grid cell to create a daily $4-\mathrm{km}$ total precipitation (PRECT), 2-m surface temperature (Tavg), minimum 2-m surface temperature (Tmin), and maximum 2-m surface temperature (Tmax), drawn from a spatially contiguous United States (CONUS) product (Daly et al. 2008). PRISM uses an empirical regression topographic correction method against elevation, atmospheric vertical layer location, coastal proximity, elevation, geographic location, orographic effectiveness, and topographic orientation. Although substantial biases in the PRISM has been addressed in many previous studies (Henn et al. 2018; Currier et al. 2017), especially in mountainous areas where observations are sparse, PRISM maintains important nonmonotonic relationships between precipitation and elevation compared with other reanalysis products such as WorldClim and Daymet (Daly et al. 2008).

The Moderate Resolution Imaging Spectroradiometer (MODIS) satellite product (MOD10CM V005) provides

TABLE 2. Metadata for the model simulations and historical reference datasets.

\begin{tabular}{|c|c|c|c|c|}
\hline Climate dataset & Hydroclimate variables & Spatial resolution & Temporal resolution & Analysis time series \\
\hline \multicolumn{5}{|c|}{ Model simulations } \\
\hline VR-CESM & $\begin{array}{l}\text { Total precipitation, snowfall, snow cover, } \\
\text { SWE, and 2-m average, minimum, and } \\
\text { maximum surface temperature }\end{array}$ & 28,14 , and $7 \mathrm{~km}$ & Daily, 6 hourly & 1999-2015 \\
\hline WRF_NCEP & Same as above & 28,14 , and $7 \mathrm{~km}$ & Same as above & Same as above \\
\hline WRF_VRCESM7 & Same as above & 28,14 , and $7 \mathrm{~km}$ & Same as above & Same as above \\
\hline WRF_VRCESM & Same as above & 28 and $14 \mathrm{~km}$ & Same as above & Same as above \\
\hline \multicolumn{5}{|c|}{ Historical reference datasets } \\
\hline SNSR & SWE & $90 \mathrm{~m}$ & Daily & 1999-2015 \\
\hline MODIS & Snow cover & $5 \mathrm{~km}$ & Monthly & $2000-2015$ \\
\hline PRISM & $\begin{array}{l}\text { Total precipitation and } 2-\mathrm{m} \text { average, } \\
\text { minimum, and maximum surface } \\
\text { temperature }\end{array}$ & $4 \mathrm{~km}$ & Daily & 1999-2015 \\
\hline
\end{tabular}


global monthly 5-km snow cover (Hall and Riggs 2015). The product is quality-assured for cloud cover by using visible and shortwave near-IR spectral bands and a snowmapping algorithm with a normalized difference snow index (NDSI). Furthermore, the MODIS products at 28, 5, and $0.5 \mathrm{~km}$ were validated against ground observations and were found to have high correlations, compared to ground stations and SNOTEL data. The lower accuracy is found in forested areas and complex terrain that vary depending on snow ephemerality and thickness (Hall and Riggs 2007). In both VR-CESM and WRF simulations, snow cover is a diagnostic variable output computed from snow density, SWE, and temperature. The analysis of snow cover data integrates both the uncertainty in observational data and biases in simulations.

The Landsat-Era Sierra Nevada Snow Reanalysis (SNSR) dataset (Margulis et al. 2016a,b) characterizes SWE for 20 watersheds within the California Sierra Nevada at 90-m resolution from 1985 to 2015. The reanalysis estimates for SWE are derived from a Bayesian data assimilation technique that utilizes 30-m elevation estimates from the ASTER and the National Land Cover Database, hourly 14-km meteorological inputs from North American Land and Data Assimilation Database phase 2 (NLDAS-2), and snow cover area and vegetation cover fractions from the NASA Landsat 5, 7, and 8 satellite products. The dataset was validated against 108 snow pillows and 202 snow course in situ SWE measurements (not incorporated into the assimilation technique) and found to linearly correlate at 0.97 across all sites. To the authors' knowledge, SNSR is the highest-quality and finest-resolution snow water equivalent reanalysis dataset over the study period covered in this paper.

\section{Results and discussions}

The analyses in this section examine the fundamental differences in how three factors influence the WRF simulation fidelity, such as the large-scale forcing dataset (section 3a) by comparing the WRF_NCEP and WRF_VRCESM7 simulations, horizontal resolution (section $3 b$ ), and the choice of dynamical core (section 3c) by comparing VR-CESM and WRF driven by VR-CESM.

\section{a. Large-scale forcing datasets}

The impact of the large-scale boundary forcing on the WRF simulations is evaluated by comparing WRF simulations driven by the NCEP reanalysis dataset and the VR-CESM simulation at the finest 7-km resolution. The WRF simulations driven by a single VR-CESM simulation are performed to assure that the three WRF simulations have the same large-scale forcing across resolutions, but allow for differences in the synoptic scales represented in NCEP and VR-CESM to be intercompared as well. First, the water year daily climate average (Fig. 3) for total precipitation and 2-m average surface temperature in the California Mountain Region and the windward and leeward sides of the Sierra Nevada are used to illustrate the differences between the two large-scale forcing datasets. A wet bias in accumulated total precipitation in the WRF_VRCESM7 simulation reaches $100-150 \mathrm{~mm}$ in the windward side of Sierra Nevada, while WRF simulations driven by NCEP have an opposing pattern to WRF_VRCESM7, with $0-100 \mathrm{~mm}$ on the windward of Sierra Nevada and even 200-300 mm dry bias throughout the California Mountain Region. The differences seen in total precipitation, snow cover, and SWE against the reference datasets (Fig. 4) provide insight into how atmospheric moisture transport and precipitation phase differed between the two large-scale forcing datasets. In WRF_VRCESM7 simulations, the DJF climate average wet biases are from +0.5 to $+0.8 \mathrm{~mm} \mathrm{day}^{-1}$ for total precipitation in WRF_VRCESM7 simulations within the California Mountain Region; however, WRF_NCEP simulations show dry biases in total precipitation between -1.3 and $-1.5 \mathrm{~mm} \mathrm{day}^{-1}$ (Fig. 5). The wet biases within the windward side of Sierra Nevada in WRF_VRCESM7 simulations are consistent to their forcing dataset, VR-CESM7 (Table 3). In general, simulated total precipitation, snow cover, and SWE are consistently overestimated on the windward side of Sierra Nevada, but underestimated on the leeward side. The stippling points in Fig. 4 also depict the precipitation bias in the California Mountain Region, particularly on the leeward side, as precipitation falls outside the variance in the mean of PRISM. A systematic dry bias in accumulated total precipitation, ranging from 160 to $220 \mathrm{~mm}$, can be found on the leeward side of the Sierra Nevada in both WRF simulations (Fig. 3). Both the WRF_NCEP and WRF_VRCESM7 simulations, had an accumulated precipitation deficit of $160-220 \mathrm{~mm}$, which was nearly $50 \%$ of the PRISM daily climatological average in the leeward side of Sierra Nevada. The total precipitation bias in the leeward side of Sierra Nevada is not driven by the large-scale forcing dataset, but rather the diagnostic treatment of rainfall and snowfall in the microphysics scheme, which inhibits precipitation to reach up to or beyond the mountain ridgeline. On the other hand, the $50-150-\mathrm{mm}$ wet bias for WRF_VRCESM7 and 60-160-mm dry bias for WRF_NCEP are less than $15 \%$ of the total accumulated precipitation in the windward side of Sierra Nevada. This again highlights that the large-scaling forcing dataset is important to precipitation 

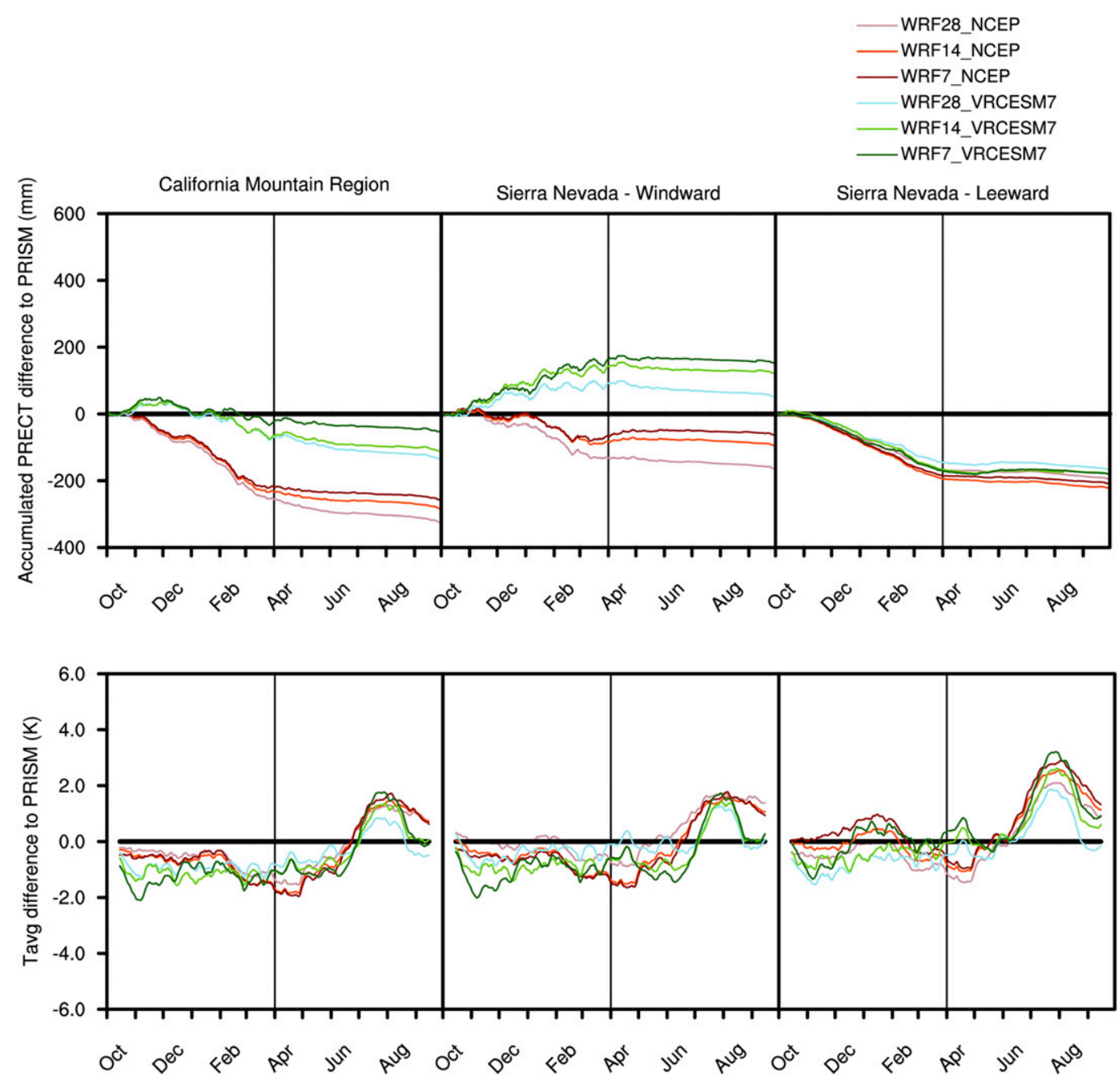

FIG. 3. Water year daily climate averages of (top) total precipitation and (bottom) surface temperature for WRF_NCEP (red) and WRF_VRCESM7 (green) ensemble members differenced from PRISM for the California Mountain Region and the windward and leeward side of the Sierra Nevada. A 30-day running average filter was applied to the surface temperature fields for clarity. The vertical black line delineates the accumulation period from the melt period at the oft-assumed historical peak accumulation date of $1 \mathrm{Apr}$.

simulation efficacy on the windward side of the Sierra Nevada.

Some statistical metrics, such as the seasonal Pearson pattern correlation, help explain the spatial bias in WRF_VRCESM7 compared to WRF_NCEP simulations. For each WRF simulation, the Pearson pattern coefficients were computed for the $16 \mathrm{DJF}$ periods across the four hydroclimatological variables listed in Table 3 over the 1999-2015 study period. The Pearson pattern coefficients of total precipitation for the WRF_VRCESM7 are smaller, indicating less skill than the WRF_NCEP simulations. This is consistent with the relatively larger bias and variability of total precipitation in WRF_VRCESM7, and is intuitive given that the VR-CESM 7-km simulation was only bounded by observed sea surface temperature and sea ice observations at monthly intervals. The comparison between WRF_VRCESM7 and WRF_NCEP indicates that the choice of large-scale forcing dataset used in the WRF simulations significantly impacts simulated total precipitation within the windward side of the mountain. However, the mountain leeward dry bias found in both NCEP-driven and VR-CESM-driven WRF simulations indicates that microphysics, rather than the large-scale forcing dataset, largely determines the proper distribution of modeled precipitation in mountainous regions, as highlighted in Rhoades et al. (2018b).

To analyze the impacts of large-scale forcing datasets on atmospheric moisture transport and precipitation, the large-scale DJF climate average integrated water vapor transport (IVT; $\mathrm{kg} \mathrm{m}^{-1} \mathrm{~s}^{-1}$ ) is presented in Fig. 6, 

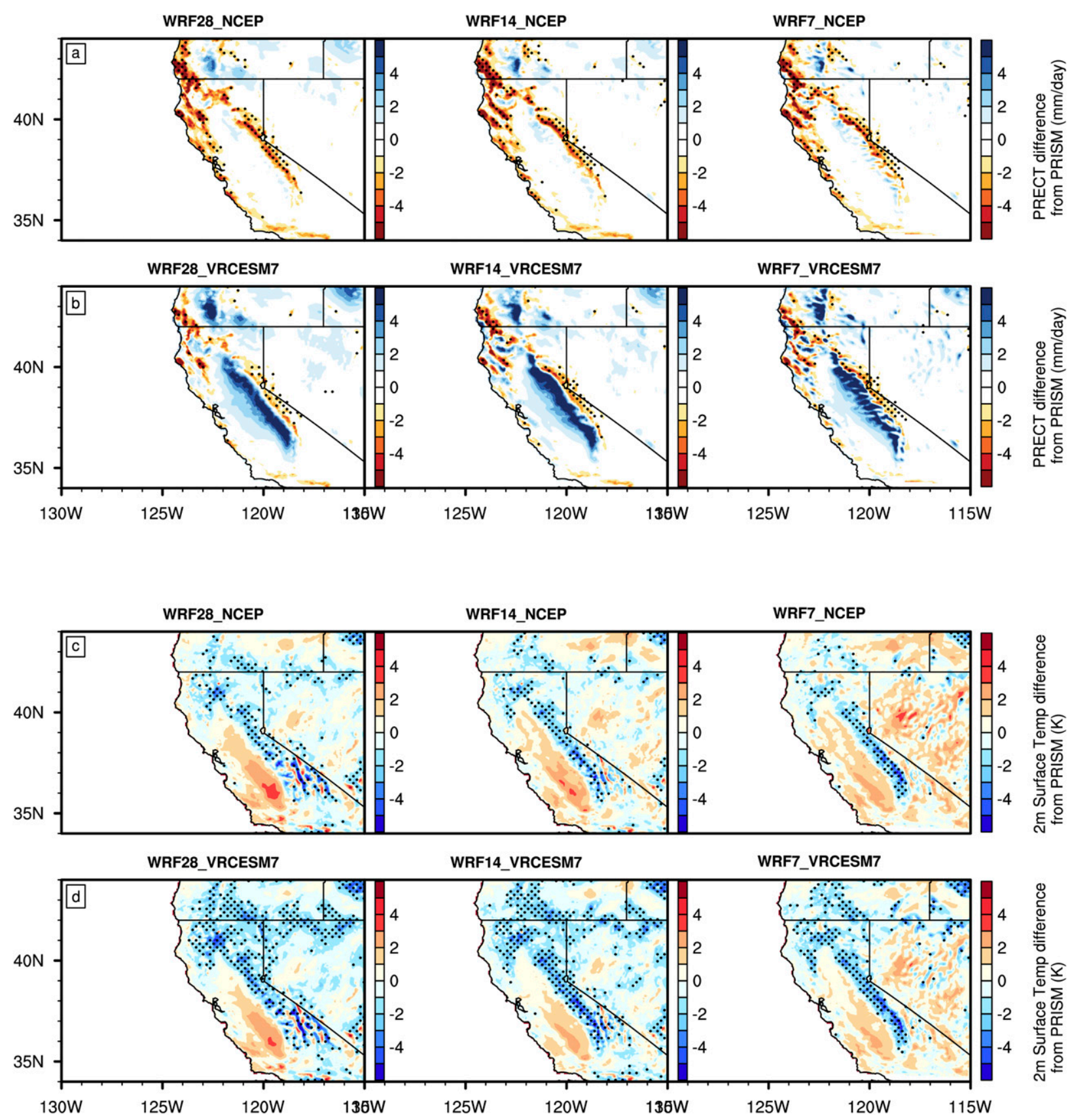

FIG. 4. Simulated DJF climate averages in WRF_NCEP and WRF_VRCESM7 across refined resolution at 28 , 14 , and $7 \mathrm{~km}$ for (a),(b) total precipitation (PRECT) against PRISM and (c),(d) daily average 2-m surface temperature (Tavg) against PRISM. Areas with statistically significance differences are marked with black stippling.

with the vector winds overlaid on the top of the IVT and topography at 500-m intervals. In general, the largescale forcing datasets determine the amount of water vapor transported and wind fields through the western boundary of the WRF domain. The IVT and wind fields in the inner WRF domain influences the simulated hydroclimatology variables in the California Mountain Region, particularly total precipitation and SWE, as it dictates the magnitude and timing of available water that can be precipitated within the California Mountain Region. The smaller IVT in the California Mountain Region in the WRF_NCEP simulations is consistent with the relatively drier simulated hydroclimatology compared to WRF_VRCESM7 (Fig. 6). The larger IVT in the California Mountain Region shown for WRF_VRCESM7 is also consistent with the wet bias in simulated 


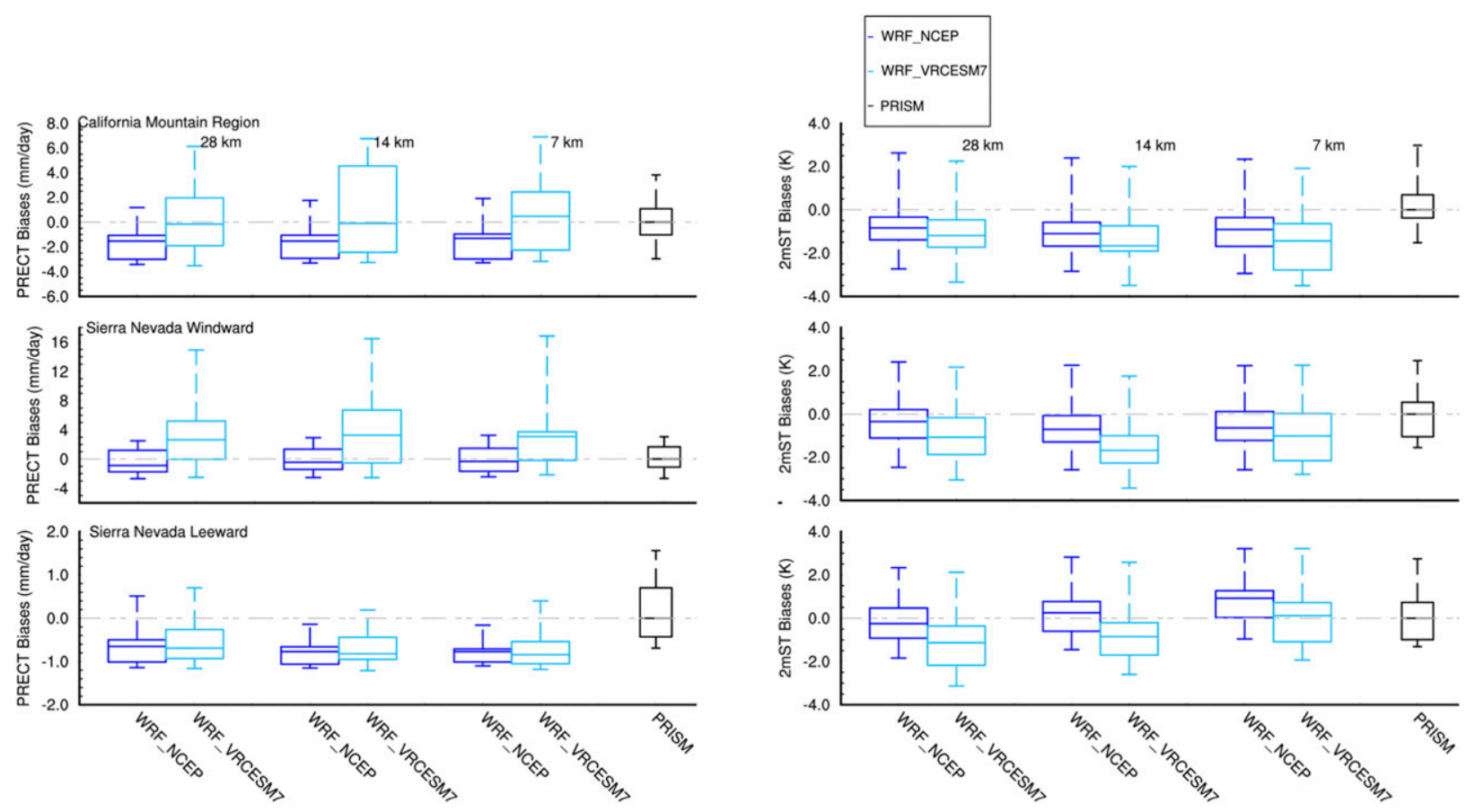

FIG. 5. The DJF average biases over the California Mountain Region in WRF simulations across resolutions, forced by NCEP (WRF_NCEP) and VR-CESM 7-km results (WRF_VRCESM7) for (left) total precipitation with respect to PRISM and (right) daily average 2-m surface temperature with respect to PRISM, in (top) California Mountain Region, (middle) Sierra Nevada windward, and (bottom) Sierra Nevada leeward.

precipitation and SWE in the California Mountain Region as well. However, as shown in comparison with the NCEP forcing dataset in Fig. 6, both WRF_NCEP and WRF_VRCESM7 simulations provide more realistic onshore winds over California due to the presence of topography. The variability of storm events, especially extremes, may have had a major impact on the WRF_NCEP and WRF_VRCESM simulations. Dettinger et al. (2011) reported that more than half of annual total precipitation falls in less than 10 days in the California Mountain Region and less than 5 days in the desert areas in Southern California. To evaluate this, we compare the number of days to $50 \%$ precipitation in our simulations (Fig. 7) to Fig. 2 from Dettinger et al. (2011). WRF_NCEP realistically simulates the spatial variability of the average numbers of days to obtain half of the total precipitation compared with findings in Dettinger et al. (2011). However, WRF_VRCESM simulations overestimate the number of days for half of the total precipitation with additional 10-15 days. This indicates that extreme precipitation is either underestimated or the storms last longer in WRF_VRCESM simulations.

As shown previously, the large-scale boundary forcing datasets are critical in determining the inner-domain hydroclimatological outcomes across most variables in the WRF simulations. California precipitation and snow are strongly related to the atmospheric moisture transport from the western boundary of the Pacific Ocean. VR-CESM simulations are solely bounded by monthly observed sea surface temperature and sea ice, whereas the NCEP reanalysis dataset is a bias-corrected product based on a data-assimilation model which utilizes various observational products (NCEP 2000). The WRF_VRCESM7 simulations had greater bias in the hydroclimate simulations than the VR-CESM simulation itself. This highlights the unique role of cascading biases between two models as the coupling of two models introduces more bias than if the models were simulated separately. However, surface temperature is more consistent across the simulations and less sensitive to large-scale forcing dataset. The lateral atmospheric heat flux provided by the large-scale forcing datasets are dissipated and augmented by regional and local scale features of California (topography, land surface cover, sea breeze, etc.) in the land surface model. Therefore, the forcing dataset has little impact on the surface temperature simulation in both WRF_NCEP and WRF_VRCESM7 simulations.

\section{b. Horizontal resolution}

The impacts of horizontal resolution are addressed and evaluated by comparing the difference in simulated 
TABLE 3. Summary statistics for winter season (DJF) seasonal hydroclimate variables by the VR-CESM, WRF_NCEP, WRF_VRCESM, and historical reference datasets within the California Mountain Region. The statistics includes 16 DJF periods from December 1999 to February 2015. The numbers in parentheses are the differences between simulations and historical reference datasets.

\begin{tabular}{|c|c|c|c|c|c|c|}
\hline Climate dataset & Mean & Std dev & Min & $\begin{array}{l}\text { Interquartile } \\
\text { range }\end{array}$ & Max & $\begin{array}{c}\text { Pearson pattern } \\
\text { correlation }\end{array}$ \\
\hline \multicolumn{7}{|c|}{ Total precipitation $\left(\mathrm{mm} \mathrm{day}^{-1}\right)$} \\
\hline VR-CESM28 & $6.95(0.88)$ & $2.82(0.99)$ & $1.72(-1.32)$ & $3.98(1.87)$ & $12.54(2.73)$ & 0.65 \\
\hline VR-CESM14 & $7.01(0.94)$ & $1.65(-0.18)$ & $4.21(1.17)$ & $2.12(0.01)$ & $9.88(0.07)$ & 0.69 \\
\hline VR-CESM7 & $7.15(1.08)$ & $3.33(1.50)$ & $2.68(-0.36)$ & $5.34(3.23)$ & $12.85(3.04)$ & 0.61 \\
\hline WRF28_NCEP & $4.55(-1.52)$ & $1.27(-0.57)$ & $2.58(-0.47)$ & $1.92(-0.19)$ & $7.18(-2.63)$ & 0.71 \\
\hline WRF14_NCEP & $4.69(-1.38)$ & $1.33(-0.50)$ & $2.70(-0.34)$ & $1.85(-0.26)$ & $7.75(-2.06)$ & 0.69 \\
\hline WRF7_NCEP & $4.77(-1.30)$ & $1.39(-0.44)$ & $2.72(-0.33)$ & $2.02(-0.09)$ & $7.91(-1.89)$ & 0.69 \\
\hline WRF28_VRCESM28 & $7.69(1.62)$ & $3.31(1.48)$ & $1.61(-1.44)$ & $5.12(3.00)$ & $13.78(3.97)$ & 0.53 \\
\hline WRF14_VRCESM14 & $7.50(1.43)$ & $2.02(0.18)$ & $4.30(1.25)$ & $2.44(0.33)$ & $11.75(1.94)$ & 0.59 \\
\hline WRF28_VRCESM7 & $6.62(0.54)$ & $3.07(1.23)$ & $2.48(0.37)$ & $3.87(1.76)$ & $12.13(2.33)$ & 0.52 \\
\hline WRF14_VRCESM7 & $6.94(0.87)$ & $3.48(1.65)$ & $2.74(0.63)$ & $6.69(4.85)$ & $12.75(2.94)$ & 0.53 \\
\hline WRF7_VRCESM7 & $6.82(0.75)$ & $3.04(1.21)$ & $2.83(-0.22)$ & $4.70(2.59)$ & $12.90(3.10)$ & 0.52 \\
\hline PRISM & $6.07(0.00)$ & $1.83(0.00)$ & $3.04(0.00)$ & $2.11(0.00)$ & $9.81(0.00)$ & 1.00 \\
\hline \multicolumn{7}{|c|}{ Snow water equivalent $(\mathrm{mm})$} \\
\hline VR-CESM28 & $57.0(-27.4)$ & $45.6(4.1)$ & $10.3(-9.7)$ & $45.4(-22.8)$ & $166.0(13.6)$ & 0.51 \\
\hline VR-CESM14 & $110.7(26.3)$ & $70.3(28.8)$ & $28.1(8.1)$ & $87.1(18.9)$ & $279.2(126.8)$ & 0.50 \\
\hline VR-CESM7 & $108.6(24.2)$ & $72.5(31.0)$ & $16.0(-4.0)$ & $141.7(73.5)$ & $215.8(63.5)$ & 0.55 \\
\hline WRF28_NCEP & $44.6(-39.8)$ & $30.0(-11.5)$ & $5.5(-14.5)$ & $51.6(-16.6)$ & $100.5(-51.9)$ & 0.44 \\
\hline WRF14_NCEP & $57.2(-27.2)$ & $35.2(-6.3)$ & $8.5(-11.5)$ & $69.2(0.9)$ & $113.8(-38.6)$ & 0.52 \\
\hline WRF7_NCEP & $64.7(-19.7)$ & $39.1(-2.4)$ & $10.5(-9.5)$ & $74.0(5.8)$ & $132.9(-19.5)$ & 0.57 \\
\hline WRF28_VRCESM28 & $92.4(8.0)$ & $53.7(12.2)$ & $26.3(6.3)$ & $72.1(3.9)$ & $196.4(44.0)$ & 0.45 \\
\hline WRF14_VRCESM14 & $113.8(29.4)$ & $46.5(5.0)$ & $48.7(28.7)$ & $59.9(-8.3)$ & $225.3(72.9)$ & 0.50 \\
\hline WRF28_VRCESM7 & $84.7(0.3)$ & $52.0(10.5)$ & $15.1(-4.9)$ & $83.3(15.1)$ & $172.6(20.3)$ & 0.42 \\
\hline WRF14_VRCESM7 & $100.5(16.1)$ & $63.0(21.5)$ & $15.0(-5.0)$ & $112.3(44.1)$ & $196.2(43.9)$ & 0.48 \\
\hline WRF7_VRCESM7 & $114.3(29.9)$ & $62.6(21.1)$ & $27.6(7.6)$ & $121.2(53.0)$ & $208.7(56.3)$ & 0.52 \\
\hline SNSR & $84.40(0.0)$ & $41.5(0.0)$ & $20.0(0.0)$ & $68.2(0.0)$ & $152.4(0.0)$ & 1.00 \\
\hline \multicolumn{7}{|c|}{ 2-m surface temperature $(\mathrm{K})$} \\
\hline VR-CESM28 & $274.0(-2.3)$ & $1.4(0.3)$ & $270.5(-4.1)$ & $1.5(0.5)$ & $276.7(-2.4)$ & 0.89 \\
\hline VR-CESM14 & $273.0(-3.3)$ & $0.9(-0.2)$ & $271.7(-2.8)$ & $1.3(0.2)$ & $274.9(-4.2)$ & 0.92 \\
\hline VR-CESM7 & $272.8(-3.6)$ & $1.3(0.2)$ & $270.5(-4.1)$ & $1.3(0.3)$ & $275.6(-3.5)$ & 0.94 \\
\hline WRF28_NCEP & $275.5(-0.8)$ & $1.3(0.2)$ & $273.4(-1.2)$ & $1.0(0.0)$ & $278.7(-0.3)$ & 0.91 \\
\hline WRF14_NCEP & $275.3(-1.0)$ & $1.3(0.2)$ & $273.3(-1.3)$ & $1.1(0.0)$ & $278.5(-0.6)$ & 0.94 \\
\hline WRF7_NCEP & $275.4(-1.0)$ & $1.3(0.2)$ & $273.2(-1.4)$ & $1.3(0.3)$ & $278.4(-0.6)$ & 0.96 \\
\hline WRF28_VRCESM28 & $275.1(-1.2)$ & $1.4(0.3)$ & $271.8(-2.8)$ & $1.7(0.6)$ & $277.7(-1.4)$ & 0.89 \\
\hline WRF14_VRCESM14 & $274.7(-1.7)$ & $0.8(-0.3)$ & $273.5(-1.1)$ & $1.5(0.4)$ & $276.0(-3.1)$ & 0.93 \\
\hline WRF28_VRCESM7 & $275.0(-1.3)$ & $1.3(0.2)$ & $272.8(-1.8)$ & $1.3(0.2)$ & $278.4(-0.7)$ & 0.90 \\
\hline WRF14_VRCESM7 & $274.7(-1.6)$ & $1.3(0.2)$ & $272.6(-2.0)$ & $1.2(0.1)$ & $278.1(-1.0)$ & 0.94 \\
\hline WRF7_VRCESM7 & $274.9(-1.5)$ & $1.4(0.3)$ & $272.6(-2.0)$ & $2.1(1.1)$ & $278.0(-1.1)$ & 0.95 \\
\hline PRISM & $276.4(0.0)$ & $1.1(0.0)$ & $274.6(0.0)$ & $1.1(0.0)$ & $279.1(0.0)$ & 1.00 \\
\hline
\end{tabular}

total precipitation and surface temperature at horizontal resolutions of 28, 14, and $7 \mathrm{~km}$ over the water year (Fig. 3). The added value of refining horizontal resolution is exhibited in total precipitation within the WRF_NCEP simulations, where the daily accumulated total precipitation bias in WRF7_NCEP is diminished by $100 \mathrm{~mm}$ from the WRF28_NCEP simulation when compared with PRISM throughout the water year. Simulated total precipitation shown in the water year daily average is likely improved from the better representation of topography and land surface cover with increasing horizontal resolution. However, the benefit of increasing horizontal resolution is not as pronounced at seasonal or climatological time scales. For example, simulated DJF average total precipitation and surface temperature in WRF do not appear to be as sensitive to the refinement of horizontal resolution (28-7 km) over the California Mountain Region in both WRF_NCEP and WRF_VRCESM7, as median and interquartile ranges overlap across horizontal resolutions (Fig. 8). Similarly, when viewed from a DJF climate perspective, the impacts of resolution and land use representation on total precipitation are vaguely apparent, with WRF_NCEP simulations exhibiting a general dry bias, especially in mountainous regions, and 

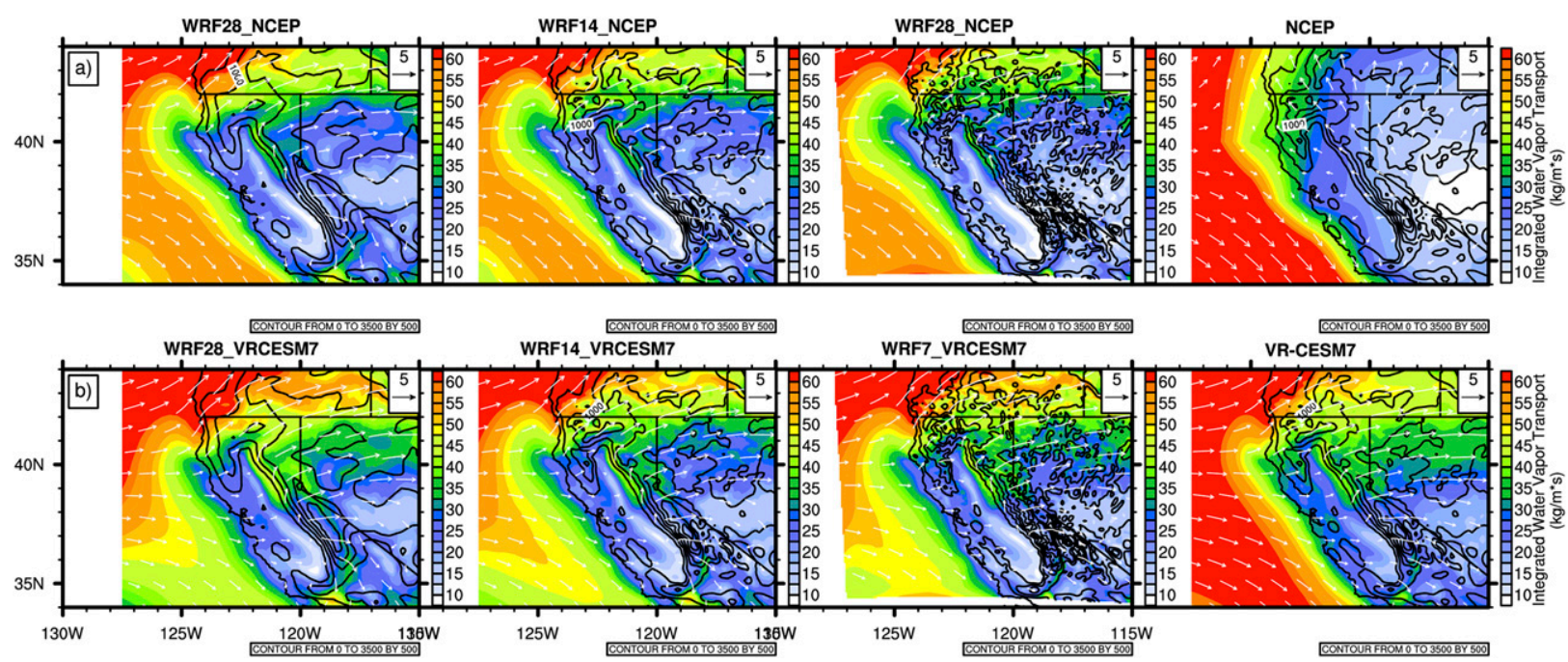

FIG. 6. Effect of large-scale forcing datasets (a) WRF_NCEP vs (b) WRF_VRCESM7 and refined horizontal grid resolution (from 28 to $7 \mathrm{~km}$ ) of DJF climate average IVT with vector winds overlaid (white arrows) and 500-m topographic contours (black lines). A $5 \mathrm{~m} \mathrm{~s}{ }^{-1}$ reference wind vector is plotted in the top-right corner of each plot.

WRF_VRCESM7 exhibiting a wet (dry) bias in windward (leeward) portions of mountainous regions (Fig. 4). This is further shown in Table 3, where no significant difference in Pearson pattern coefficients are found across horizontal resolution in WRF_NCEP (WRF_VRCESM) simulations with DJF climate average values ranging between 0.69 and 0.71 (between 0.52 and 0.59).

On the other hand, increasing horizontal resolution does eliminate some of the biases when viewed in the context of surface temperature, especially in certain localized regions. For example, the surface temperature biases decrease from the 28 - to $14-\mathrm{km}$ simulations, and slightly improve when going from 14 to $7 \mathrm{~km}$ in the southern Central Valley and leeward side of the southern Sierra Nevada. The alleviation of surface temperature bias is probably related to the improved details in topography and land cover in the finer-resolution simulations. However, the cold bias in the California
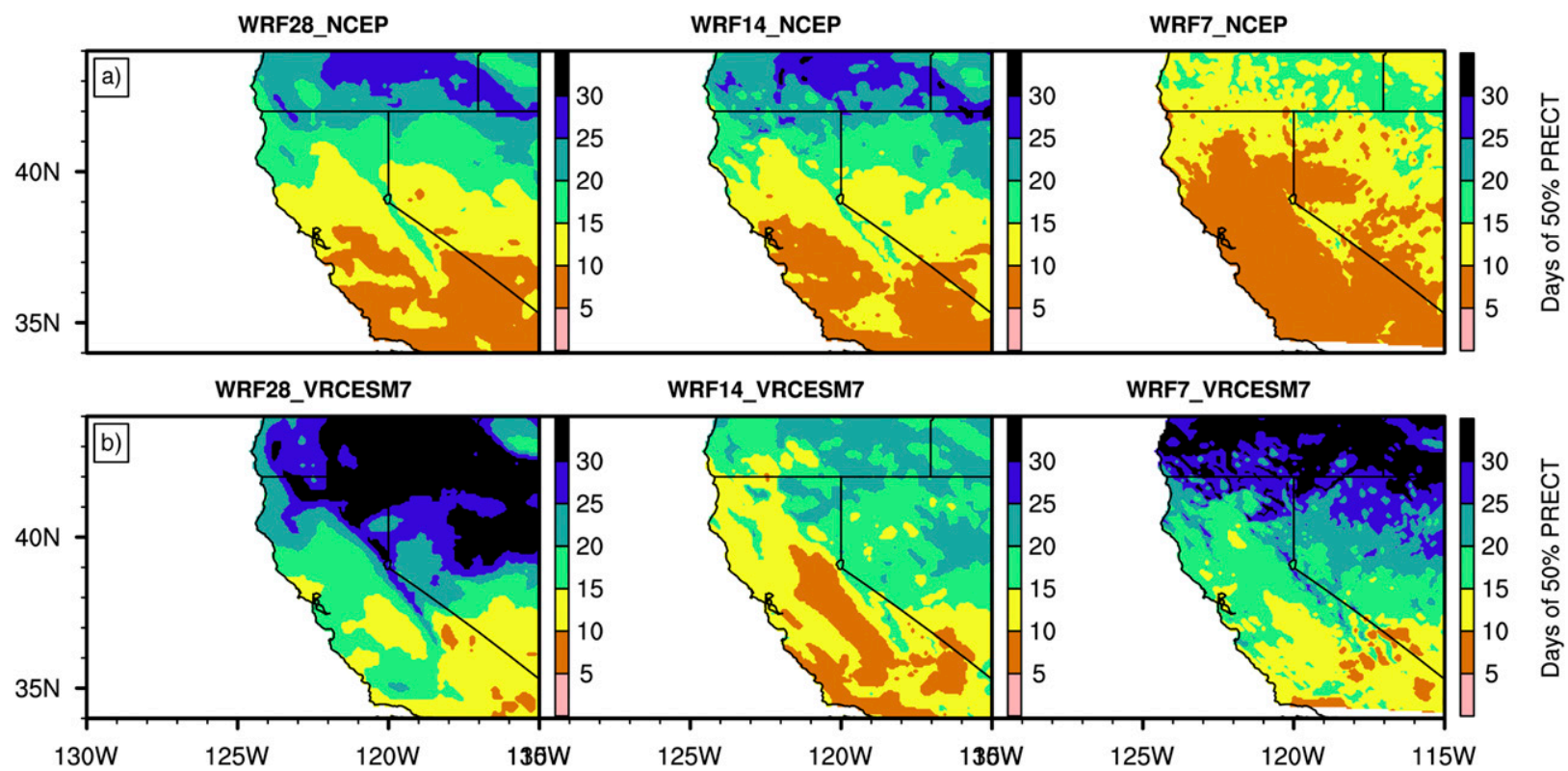

FIG. 7. Average number of days per water year to obtain half of total precipitation for (a) WRF_NCEP and (b) WRF_VRCESM simulations. 

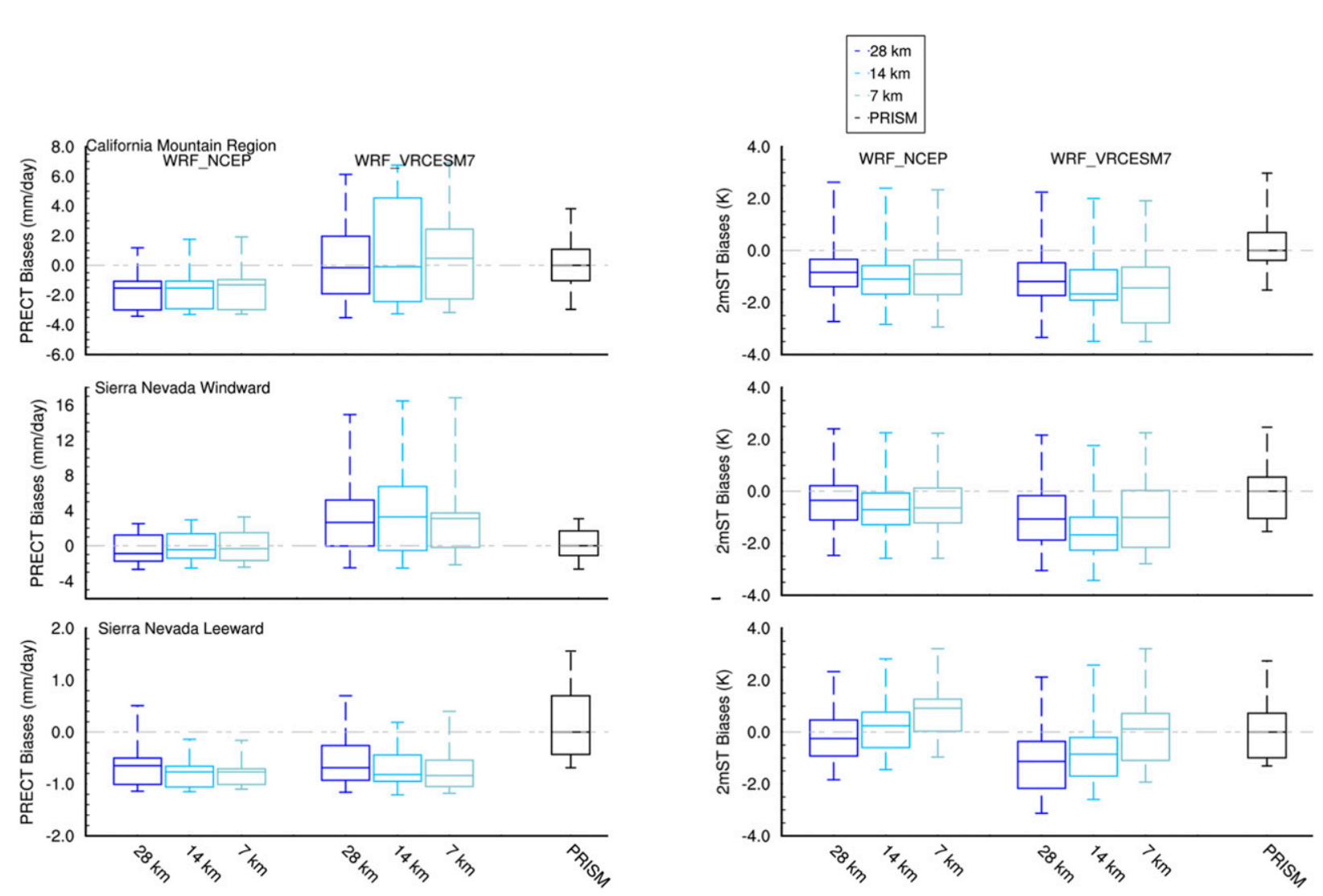

FIG. 8. The DJF average biases over the California Mountain Region in both WRF_NCEP and WRF_VRCESM7 simulations across resolutions at 28,14, and $7 \mathrm{~km}$ for (left) total precipitation with respect to PRISM and (right) daily average 2-m surface temperature with respect to PRISM, in (top) California Mountain Region, (middle) Sierra Nevada windward, and (bottom) Sierra Nevada leeward.

Mountain Region remains as horizontal resolution is refined from 28 to $7 \mathrm{~km}$ at daily (Fig. 3), seasonal (Fig. 8), and climate average (Fig. 4) time scales, save for the leeward side of the Sierra Nevada. The model biases are statistically important and marked by the stippling points in Fig. 4, as the temperature biases are below the PRISM mean minus the observed variance throughout the California Mountain Region. This indicates that although topography may be more realistically represented at finer resolution, this does not necessarily improve the representation of surface temperature. For instance, surface temperature is also controlled by localized processes such as radiation aspect, humidity, boundary layer mixing, snow albedo feedback, and cloud cover and duration.

Therefore, a more accurate representation of topography and land cover in either VR-CESM or WRF is not the only requirement to better simulate the overall hydroclimatology of California. This conclusion is similar to Rhoades et al. (2018b), who found that there was not a significant benefit from simply refining model horizontal resolution alone, but rather, a refinement of horizontal resolution coupled with a modification in how precipitation is treated in the microphysics scheme led to better overall hydroclimatological simulations. For example, MG1 simulations at $\leq 28 \mathrm{~km}$ precipitate too fast as a result of erroneous constraints in gridcell precipitation transport as storms were orographically uplifted, akin to what is shown in Fig. 4 in the windward (leeward) high (low) bias in total precipitation. Nevertheless, the differences between WRF_NCEP and WRF_VRCESM7 simulations highlight that large-scale forcing datasets in RCMs are significant contributors in shaping regional hydroclimatology. This analysis indicates that more accurate hydroclimate simulations over California will come from the use of observationally consistent large-scale forcing rather than model horizontal resolution alone.

\section{c. Dynamical cores}

The sensitivities that emerge from the choice of dynamical core are now addressed by comparing the differences between WRF_VRCESM and VR-CESM simulations in both winter and summer seasons. In the discussion of dynamical core choice, VR-CESM simulations are compared with WRF_VRCESM driven by VR-CESM simulations at the same refined resolution as the RCM, namely, WRF28_VRCESM28, WRF14_VRCESM14, and 

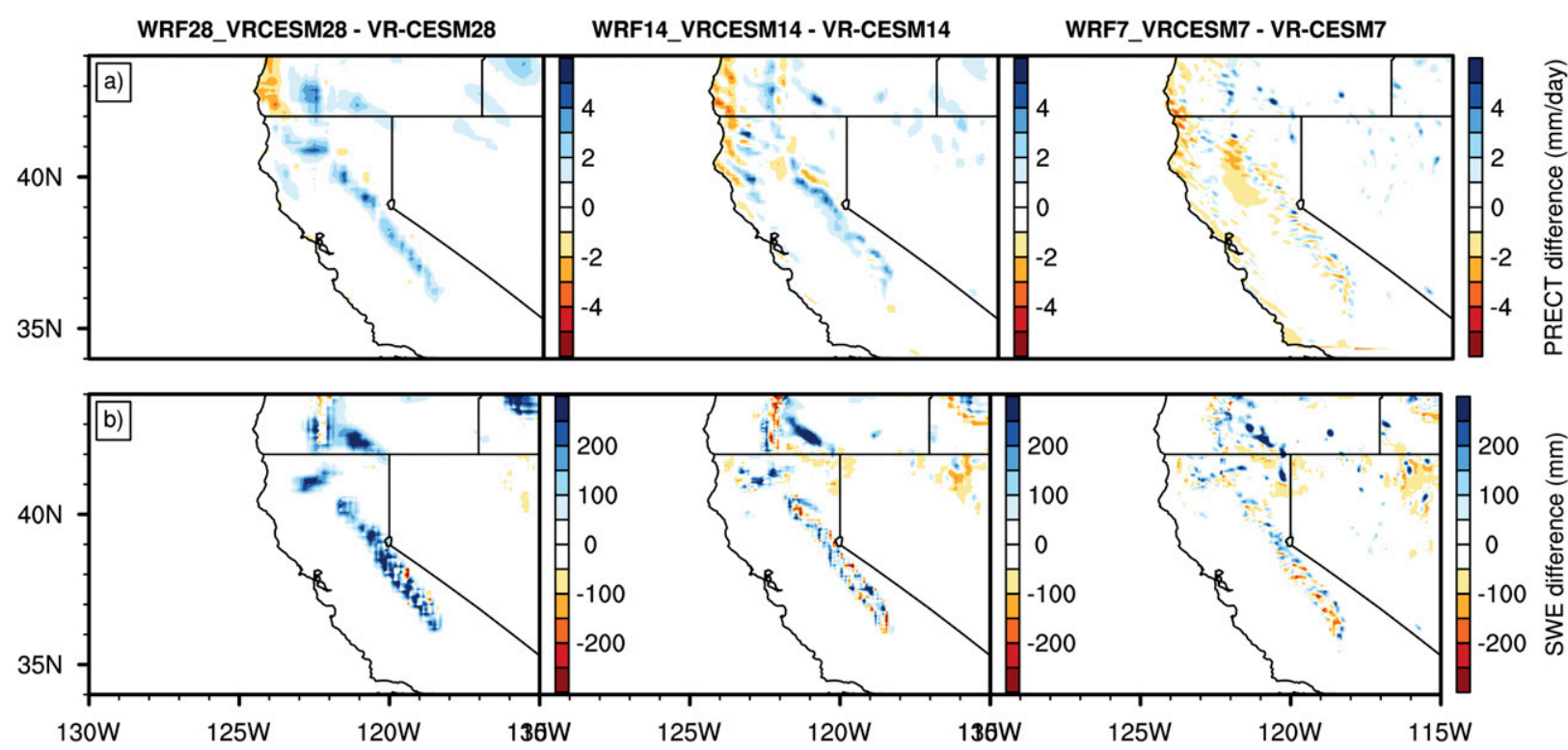

FIG. 9. Spatial differences between WRF_VRCESM and VR-CESM for (a) DJF climate average PRECT and (b) SWE on 28 Feb.

WRF7_VRCESM7. This was done to ensure consistent large-scale boundary conditions in the intercomparison between RCMs and their forcing VRGCM dataset.

The differences in DJF climate average total precipitation and climate average SWE on 28 February between WRF_VRCESM and VR-CESM simulations are presented in Fig. 9. The SWE on 28 February was selected as the metric for evaluating snowpack accumulation and snowmelt during winter seasons, because the average of an integrated quantity does not have a well-defined meaning. The DJF climate average precipitation is largely insensitive to dynamical core choice, with less than $\pm 1.0 \mathrm{~mm}$ day $^{-1}$ difference between WRF_VRCESM and VR-CESM simulations across resolutions. The Pearson pattern correlations of total precipitation for the VR-CESM simulations are generally larger than WRF_VRCESM (Table 3). This implies a degradation of the seasonal spatial match to the reference datasets in the VR-CESM simulations occurred when the large-scale conditions simulated in VR-CESM were forced at the boundaries of the WRF domain, likely due to the multimodel bias propagation discussed before. Unlike total precipitation, simulated SWE in WRF_VRCESM simulations is consistently larger than VR-CESM throughout the California Mountain Region, particularly at $28 \mathrm{~km}$ horizontal resolution (Fig. 9). Additionally, WRF_VRCESM overestimates snow cover in the California Mountain Region but underestimates in the Great Basin, which is partially explained by the warm bias in the inland desert area shown in Fig. 10. Of particular importance to findings highlighted in Rhoades et al. (2018b), WRF_VRCESM surface temperature in DJF were much warmer over the entire study region compared to VR-CESM simulations. The surface temperature cold biases from -2.3 to $-3.6 \mathrm{~K}$ against PRISM in the California Mountain Region observed in the VR-CESM simulations are alleviated to from -0.2 to $-0.6 \mathrm{~K}$ in the WRF_VRCESM simulations (Table 3).

To evaluate one of the potential drivers of DJF climate surface temperature in the California Mountain Region, the snow-albedo feedback, the relationship of daily climate snow cover and surface temperature, is shown in Fig. 11. The plots represent the normalized daily climate average differences of WRF_NCEP and WRF_VRCESM simulations from the historical reference datasets for snow cover (MODIS) and average surface temperature (PRISM). Normalization was used to highlight trend, rather than magnitude, and isolate when snow cover and temperature were either correlated or anticorrelated. The normalized snow cover daily trends show a striking day-to-day similarity across the simulations. A clear correlation after the historical peak timing date appears between snow cover and surface temperature before the historical peak timing date that switches to an anticorrelation afterward. The correlation between daily climate snow cover and surface temperature after the historical peak timing data is likely because snow cover, and hence albedo, is reduced then leads to increased surface temperature, due to less solar energy being absorbed at the surface. The anticorrelation between daily climate snow cover and temperature after the historical peak timing date is likely due to the onset of higher snow line variability which 
WRF28_VRCESM28 - VR-CESM28

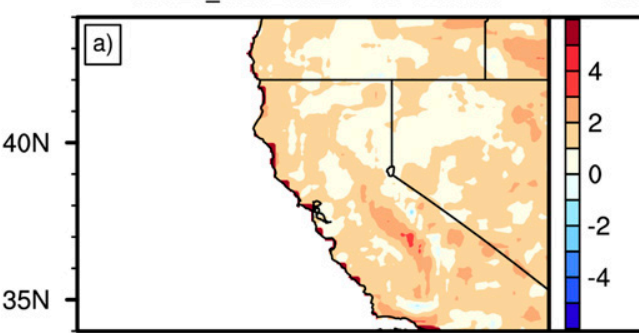

WRF14_VRCESM14 - VR-CESM14

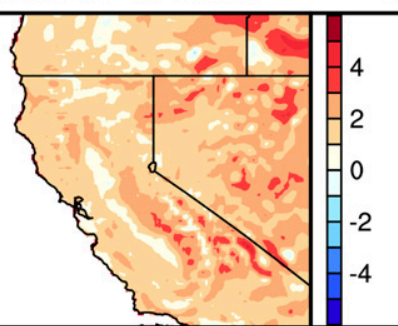

WRF7_VRCESM7 - VR-CESM7

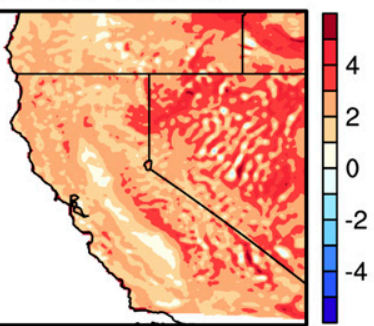

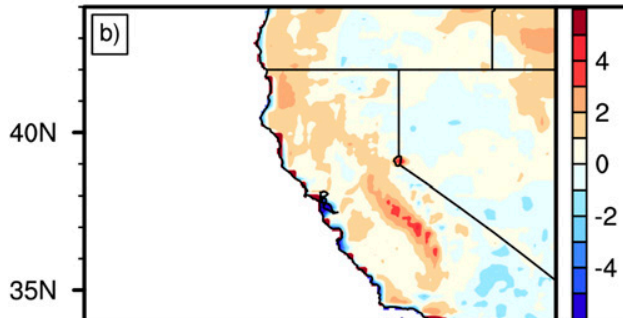
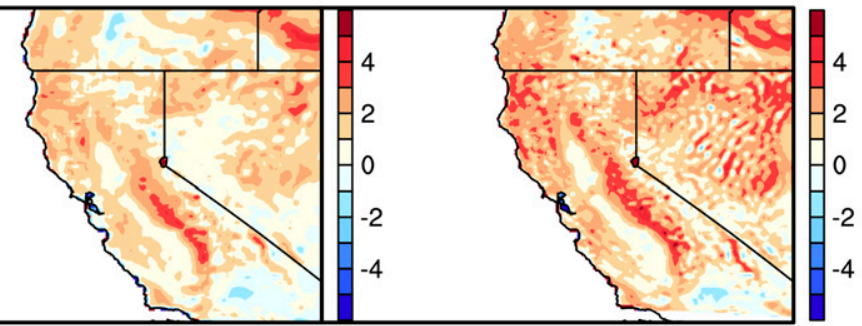

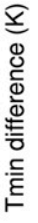

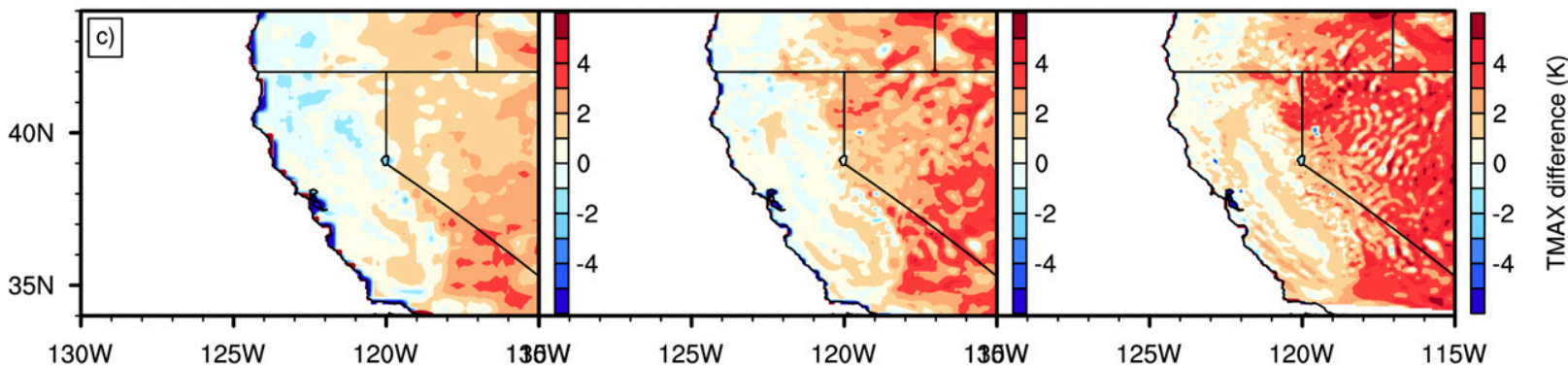

FIG. 10. Spatial differences in DJF climate averages between WRF_VRCESM and VR-CESM for (a) Tavg, (b) Tmin, and (c) Tmax.

diminishes the role of the snow-albedo feedback. Some of the variability in average surface temperature can be explained prior to the historical peak timing date by snow cover, namely in DJF, where a spread in snow cover is seen across WRF_NCEP and WRF_VRCESM simulations coinciding with a spread in average surface temperature, particularly in the leeward side of the Sierra Nevada. However, after the historical peak timing date the difference in daily climate snow cover between WRF_NCEP and WRF_VRCESM simulations is much more constrained, yet the daily climate surface temperatures are much more varied. As mentioned in Miller et al. (2008), it is difficult to fully understand the DJF temperature differences without the assessment of the differences in specified land characteristics, including vegetation and soil types, surface roughness, and albedo, as well as radiative fluxes and near-surface meteorological parameters. A more thorough evaluation of each of these land surface drivers and how they shape surface temperature is outside the scope of this study, but will be conducted in future research.

In spring-to-summer months, WRF_VRCESM surface temperatures are consistently warmer throughout the California Mountain Region, compared to VR-CESM, shown via the JJA climate average in Fig. 12. The warmer simulated JJA average and minimum surface temperature in WRF_VRCESM shown throughout the California Mountain Region indicates that the $\sim 3 \mathrm{~K}$ cold bias in VR-CESM (Fig. 13) is significantly alleviated in the WRF simulations. However, the average and minimum surface temperature differences in WRF_VRCESM and VR-CESM exhibit distinct patterns in the regions. WRF_VRCESM simulations have a colder JJA climate average and minimum surface temperature. This results in an alleviation of the warm biases in the Central Valley and an increase in surface temperature in the Great Basin, as shown in Fig. 13. Maximum surface temperature becomes a more important parameter during summer seasons, considering that extreme heat conditions are closely related to the drought conditions. To partially evaluate this key phenomena, Fig. 12 shows the simulated surface temperature maximum in WRF_VRCESM. WRF_VRCESM is 0.3-1.4 K warmer than the VR-CESM simulations and has a significant warm bias over the Central Valley, considering VR-CESM already had a $1.3-1.6 \mathrm{~K}$ warm 

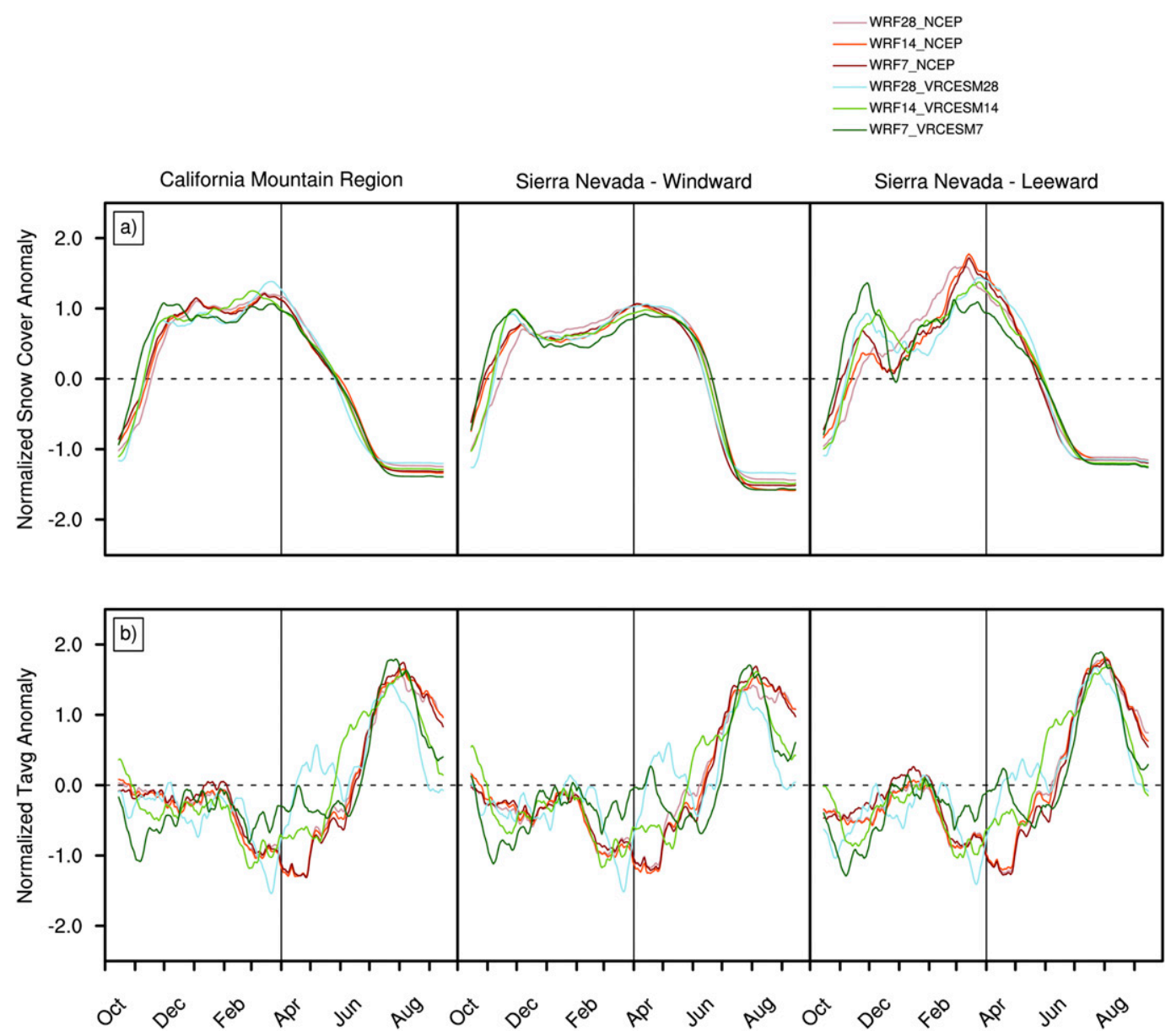

FIG. 11. The normalized water year daily climate average of (a) snow cover (SNOWC) and (b) Tavg. The solid black line delineates the historical snowpack peak timing date (1 Apr).

bias (Fig. 13). The overestimation of maximum surface temperature by WRF raises concerns of properly simulating the summertime heat waves in the Central Valley, which are important to the agriculture industry and water supply assessments (Hayhoe et al. 2004).

The overestimation of simulated average and maximum surface temperatures during summer seasons has been discussed in many studies (Mahmood et al. 2006; Bonfils and Lobell 2007), particularly in California's Central Valley (Lo and Famiglietti 2013; Sorooshian et al. 2011; Kanamaru and Kanamitsu 2008). The inaccurate estimation of soil moisture associated with irrigation and other human activities is believed to be an important factor for the warm bias in the Central Valley. Caldwell et al. (2009) pointed out that the underprediction of JJA soil moisture enhanced the surface heating. This study corroborates this finding in our own evaluation of maximum surface temperature in both the VR-CESM and WRF simulations within the Central Valley. The warm bias of maximum surface temperature and heat wave statistics in California's Central Valley were also reported in Miller et al. (2008) and Huang and Ullrich (2016), and were attributed to the lack of irrigation parameterization in the model. In general, the maximum surface temperature bias over the Central Valley in this study is consistent with prior VR-CESM and WRF simulations that did not utilize irrigation parameterizations. However, few studies have evaluated the large warm bias in simulated surface temperature over the Great Basin. This may warrant further investigation into the accuracy of the historical reference datasets and/or the model efficacy in simulating temperature variables in the arid desert regions that have very low soil moisture.

The sensitivity of the simulated hydroclimate, particularly surface temperature, to the dynamical core choice in VR-CESM and WRF is clearly shown. Dynamical core choice is intuitively an important factor as it shapes the dynamics and thermodynamics of the simulated atmospheric system. More studies are needed to elucidate 

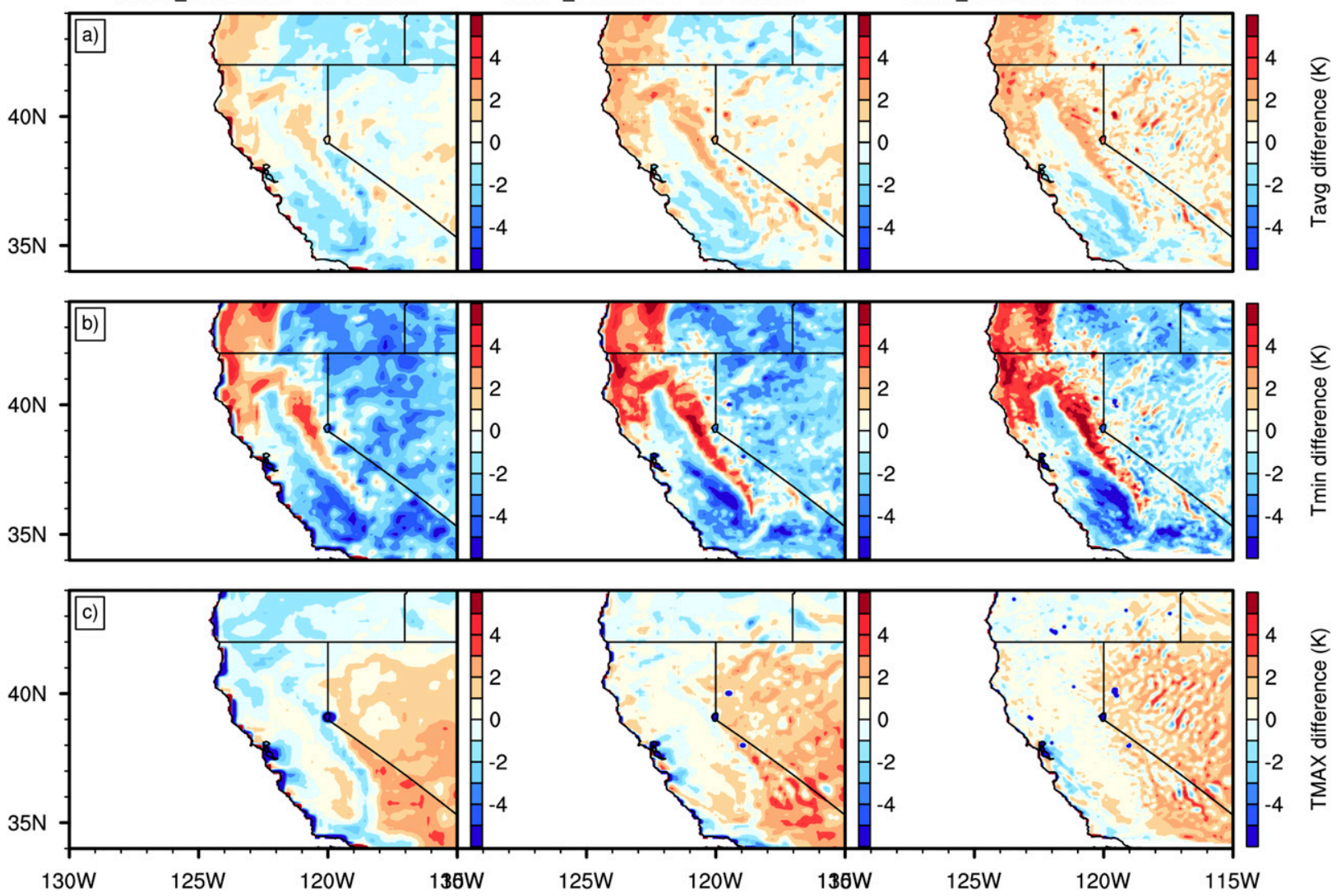

FIG. 12. Spatial differences in JJA climate averages between WRF_VRCESM and VR-CESM for (a) Tavg, (b) Tmin, and (c) Tmax.

the processes that the choice of dynamical core has on simulated temperature, particularly the effect of snow cover on temperature simulations and atmosphere-land interaction. Additionally, upscale effects associated with how regional refinement within VR-CESM impacts the global scale climatology (especially downwind) need to be further understood. Future work will attempt to bound the VR-CESM simulations global domain with NCEP reanalysis and run the inner domain akin to the WRF_NCEP simulations in this study. This will afford a more equal comparison with the WRF_NCEP simulations to better understand dynamical core choice and isolate some of the aforementioned upscale and downwind effects in the VR-CESM approach.

\section{Conclusions}

The historical hydroclimatology of California and Nevada were simulated over 1999-2015 by two state-ofthe-art dynamical downscaling methods, VR-CESM and WRF. The WRF simulations focused over California and Nevada are driven by the NCEP reanalysis dataset and VR-CESM results in Rhoades et al. (2018b).
The relative influence of large-scale forcing dataset (WRF_VRCESM7 and WRF_NCEP), horizontal resolution $(28,14$, and $7 \mathrm{~km})$, and dynamical core choice (WRF and VR-CESM) were evaluated. The implications of these three major factors in shaping the simulated hydroclimate over California and Nevada were as follows:

1) The large-scale forcing datasets used in the WRF simulations, specifically NCEP and VR-CESM7, are critical for modeling the hydroclimatology of California and Nevada, especially in mountainous regions. Compared with the wet bias of total precipitation and SWE in WRF_VRCESM7, WRF simulations driven by the NCEP reanalysis dataset generated a dry bias in total precipitation and SWE. Total precipitation and SWE are sensitive to largescale forcing datasets as they often determine the atmospheric moisture transport from the Pacific Ocean at the western boundary of the RCM. We find that coupling WRF and VR-CESM leads to an increased bias in total precipitation, especially on the windward side of Sierra Nevada, likely due to the bias cascading from global to regional models. 

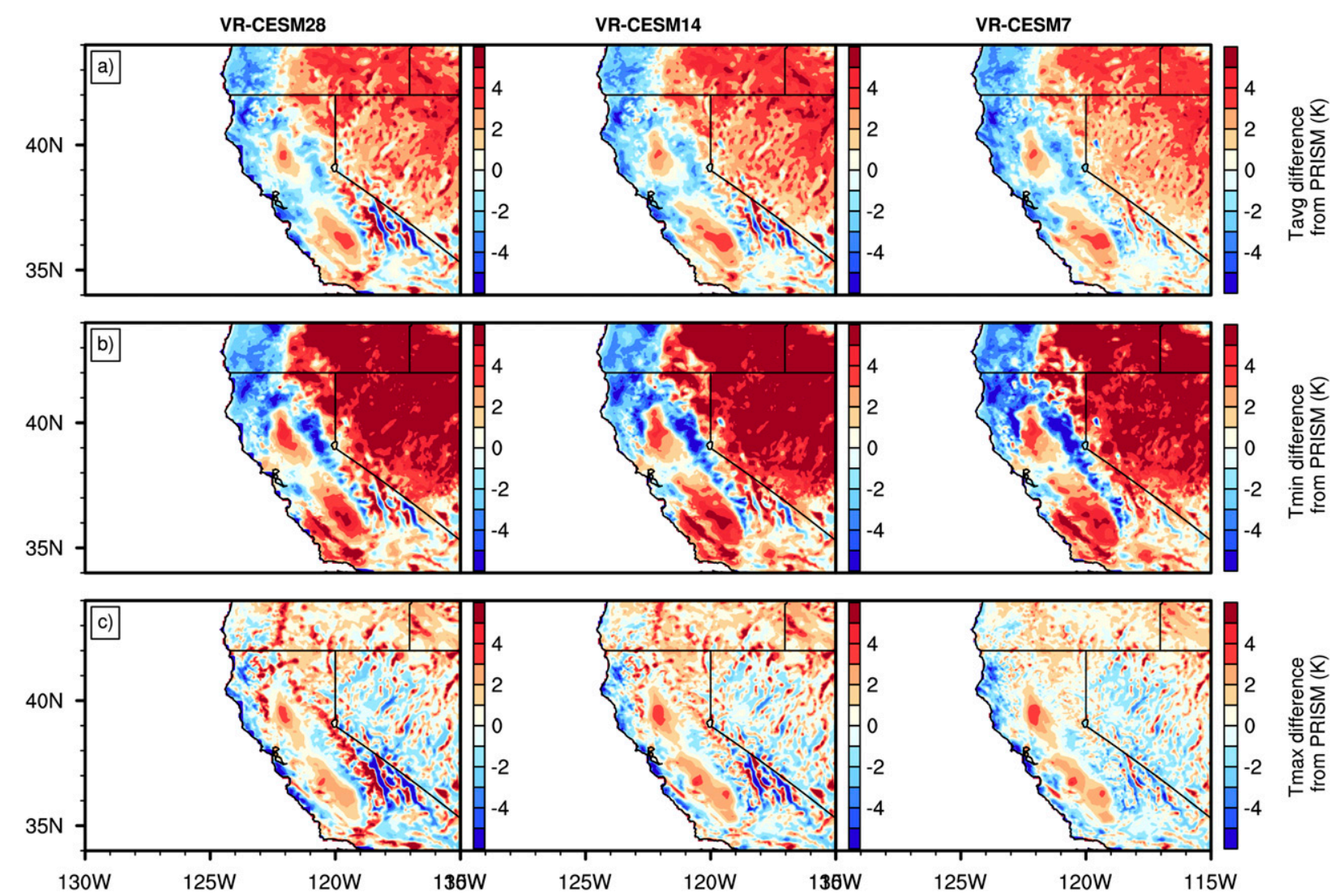

FIG. 13. Simulated DJF climate averages in VR-CESM across refined resolution at 28, 14, and $7 \mathrm{~km}$ for (a) Tavg against PRISM, (b) Tmin against PRISM, and (c) Tmax against PRISM.

However, the simulated surface temperature variables (minimum, average, and maximum) are not sensitive to the forcing dataset. Temperature at the western lateral boundaries of the outermost domain for both VR-CESM and WRF simulations are actually forced by the prescribed sea surface temperature dataset, which is an error-corrected reanalysis dataset as well. Boundary conditions have little impact on surface temperature, which is mainly determined by the land surface model with little lateral heat exchange (Oleson et al. 2010). Therefore, the trivial differences in simulated temperature may depend more on regional climate drivers (e.g., SSTs, topography, and land cover) than the large-scale forcing dataset (e.g., NCEP or VR-CESM7).

2) The refinement of horizontal resolution in WRF and VR-CESM at 28, 14, and $7 \mathrm{~km}$ did not necessarily result in an overall better simulated hydroclimatology in California or Nevada. Compared to the reference datasets, minor improvements are found with increasing model horizontal resolution alone, even though a better representation of mountain topography and land cover was apparent. The weak impact of solely refining model horizontal resolution was also noted and evaluated in greater detail in Rhoades et al. (2018b) and attributed to the limited capability of diagnostic microphysics schemes in properly advecting precipitation at more refined resolutions. The only benefit of horizontal resolution refinement was found in total precipitation on the windward side of the Sierra Nevada in WRF_NCEP simulations. This exception highlights that high-quality, largescale forcing datasets (i.e., bias-corrected reanalysis datasets) can ameliorate some of the WRF precipitation biases in regions that do not depend on the downstream advection of precipitating particles.

3) The choice of dynamical core is one of the major differences between the WRF and VR-CESM downscaling methods when evaluated with consistent atmospheric physics, land surface schemes, and boundary conditions. The differences in simulated total precipitation between the choice of dynamical cores in VR-CESM and WRF driven by VR-CESM are not clearly shown. However, WRF_VRCESM exhibits a systematically warmer DJF surface temperature over the California Mountain Region than VR-CESM 
and is more closely aligned with the PRISM reference dataset. The underestimation of snow cover is believed as a potential reason for the warmer simulated temperature in the winter season. The significant impact of atmospheric dynamical core choice on simulated surface temperature is surprising because the difference in vertical velocity computation is usually believed to be a key factor for solving precipitation and/or wind speed and less of an impact on surface temperature variables. On the other hand, the JJA climate average maximum surface temperature in WRF simulations is consistently overestimated in the California Central Valley in both WRF_VRCESM and WRF simulations. The warm bias of JJA maximum surface temperature in the Central Valley is possibly related to the soil moisture estimation and lack of irrigation scheme used in the WRF simulations.

4) Further investigations, such as an intercomparison of different land surface models and a sensitivity analysis of the key processes between the atmospheric and land, are required to further understand some biases. As mentioned, the choice of atmospheric dynamical core plays an important role in simulating the surface temperature. The anticorrelation between annual snow cover and temperature variables indicates that snowalbedo feedback on surface temperature is an important factor, especially in shaping the land surface energy budgets during the winter season. An energy budget analysis and intercomparison using different land surface models would be helpful to understand temperature biases shown in this study. Additionally, the irrigation impacts on soil moisture and temperature simulations during the summer season highlight that the physics schemes used are deterministic for simulated variables. Last, as shown in Rhoades et al. (2018b), the choice of prognostic versus diagnostic microphysics in atmospheric models plays a large role in how well distributed the precipitation is within the windward and leeward side of mountainous regions, especially snowfall. This study only utilized the diagnostic microphysics scheme (MG1) developed by Morrison and Gettelman (2008), rather than the new prognostic microphysics scheme (MG2) shown in Gettelman and Morrison (2015), due to MG2 not being available in WRF. The use of MG1 most likely led to the large biases in mountain windward/leeward distributions in hydroclimate variables, namely, precipitation, snow cover, and SWE, and should be further assessed for cascading effects into the other spatial and temporal analyses.

Acknowledgments. This research is funded by Lawrence Berkeley National Laboratory (LBNL) Lab Directed
Research and Development (LDRD 103912) Program, "Modeling the Earth's Hydrological Cycle from Watershed to Global Scales" project. This research used the Lawrencium computational cluster resource provided by the IT Division at the Lawrence Berkeley National Laboratory (Supported by the Director, Office of Science, Office of Basic Energy Sciences, of the U.S. Department of Energy under Contract DE-AC0205CH11231), and the National Energy Research Scientific Computing Center, a DOE Office of Science User Facility supported by the Office of Science of the U.S. Department of Energy under Contract DE-AC0205CH11231. Support for authors A.M. Rhoades and P.A. Ullrich is also provided by the U.S. DOE Office of Science project "An Integrated Evaluation of the Simulated Hydroclimate System of the Continental U.S." (Contract DE-SC0016605). The authors would like to thank the editor Dr. Ruby Leung and two anonymous reviewers for their constructive comments and suggestions in the review process.

\section{REFERENCES}

Boberg, F., and J. H. Christensen, 2012: Overestimation of Mediterranean summer temperature projections due to model deficiencies. Nat. Climate Change, 2, 433-436, https://doi.org/ 10.1038/nclimate1454.

Bonfils, C., and D. Lobell, 2007: Empirical evidence for a recent slowdown in irrigation-induced cooling. Proc. Natl. Acad. Sci. USA, 104, 13 582-13 587, https://doi.org/10.1073/pnas.0700144104.

Bretherton, C. S., and S. Park, 2009: A new moist turbulence parameterization in the Community Atmosphere Model. J. Climate, 22, 3422-3448, https://doi.org/10.1175/2008JCLI2556.1.

Caldwell, P., H.-N. S. Chin, D. C. Bader, and G. Bala, 2009: Evaluation of a WRF dynamical downscaling simulation over California. Climatic Change, 95, 499-521, https://doi.org/ 10.1007/s10584-009-9583-5.

California Data Exchange Center, 2016: California Department of Water Resources Northern Sierra 8 Station Index. California Data Exchange Center, http://cdec.water.ca.gov/cgi-progs/ precip1/8STATIONHIST.

Cayan, D. R., E. P. Maurer, M. D. Dettinger, M. Tyree, and K. Hayhoe, 2008: Climate change scenarios for the California region. Climatic Change, 87, 21-42, https://doi.org/10.1007/ s10584-007-9377-6.

Chin, H.-N. S., 2008: Dynamical downscaling of GCM simulations: Toward the improvement of forecast bias over California. Lawrence Livermore National Laboratory Tech. Rep. LLNLTR-407576, 16 pp., https://e-reports-ext.llnl.gov/pdf/ 365755.pdf.

Christensen, J. H., T. R. Carter, M. Rummukainen, and G. Amanatidis, 2007: Evaluating the performance and utility of regional climate models: The prudence project. Climatic Change, 81, 1-6, https://doi.org/10.1007/s10584-006-9211-6.

— F. Boberg, O. B. Christensen, and P. Lucas-Picher, 2008: On the need for bias correction of regional climate change projections of temperature and precipitation. Geophys. Res. Lett., 35, L20709, https://doi.org/10.1029/2008GL035694. 
Collins, W. D., and Coauthors, 2006: The Community Climate System Model version 3 (CCSM3). J. Climate, 19, 2122-2143, https://doi.org/10.1175/JCLI3761.1.

Currier, W. R., T. Thorson, and J. D. Lundquist, 2017: Independent evaluation of frozen precipitation from WRF and PRISM in the Olympic Mountains. J. Hydrometeor., 18, 2681-2703, https:// doi.org/10.1175/JHM-D-17-0026.1.

Daly, C., M. Halbleib, J. I. Smith, W. P. Gibson, M. K. Doggett, G. H. Taylor, J. Curtis, and P. P. Pasteris, 2008: Physiographically sensitive mapping of climatological temperature and precipitation across the conterminous United States. Int. J. Climatol., 28, 2031-2064, https://doi.org/10.1002/joc.1688.

Dettinger, M. D., and M. L. Anderson, 2015: Storage in California's reservoirs and snowpack in this time of drought. San Francisco Estuary Watershed Sci., 13, 1-5, https://doi.org/10.15447/ sfews.2015v13iss2art1.

—_, F. M. Ralph, T. Das, P. J. Neiman, and D. R. Cayan, 2011: Atmospheric rivers, floods and the water resources of California. Water, 3, 445-478, https://doi.org/10.3390/ w3020445.

Frei, C., J. H. Christensen, M. Déqué, D. Jacob, R. G. Jones, and P. L. Vidale, 2003: Daily precipitation statistics in regional climate models: Evaluation and intercomparison for the European Alps. J. Geophys. Res., 108, 4124, https://doi.org/ 10.1029/2002JD002287.

Gettelman, A., and H. Morrison, 2015: Advanced two-moment bulk microphysics for global models. Part I: Off-line tests and comparison with other schemes. J. Climate, 28, 1268-1287, https://doi.org/10.1175/JCLI-D-14-00102.1.

, P. Callaghan, V. E. Larson, C. M. Zarzycki, J. Bacmeister, P. H. Lauritzen, P. A. Bogenschutz, and R. Neale, 2018: Regional climate simulations with the Community Earth System Model. J. Adv. Model. Earth Syst., 10, 1245-1265, https:// doi.org/10.1002/2017MS001227.

Giorgi, F., and W. J. Gutowski, 2015: Regional dynamical downscaling and the CORDEX initiative. Annu. Rev. Environ. Resour., 40, 467-490, https://doi.org/10.1146/annurev-environ102014-021217.

—_, C. Jones, and G. R. Asrar, 2009: Addressing climate information needs at the regional level: The CORDEX framework. WMO Bull., 58 (3), 175-183, http://wcrp.ipsl.jussieu.fr/ cordex/documents/CORDEX_giorgi_WMO.pdf.

Gutowski, W. J., Jr., and Coauthors, 2016: WCRP Coordinated Regional Downscaling Experiment (CORDEX): A diagnostic MIP for CMIP6. Geosci. Model Dev., 9, 4087-4095, https:// doi.org/10.5194/gmd-9-4087-2016.

Gutzler, D. S., and T. O. Robbins, 2011: Climate variability and projected change in the western United States: Regional downscaling and drought statistics. Climate Dyn., 37, 835-849, https://doi.org/10.1007/s00382-010-0838-7.

Hall, D. K., and G. A. Riggs, 2007: Accuracy assessment of the MODIS snow products. Hydrol. Processes, 21, 1534-1547, https://doi.org/10.1002/hyp.6715.

— Global 0.05Deg CMG, version 6. National Snow and Ice Data Center Distributed Active Archive Center, accessed 2016, https://doi.org/10.5067/MODIS/MOD10CM.006.

Harris, L. M., and S.-J. Lin, 2013: A two-way nested global-regional dynamical core on the cubed-sphere grid. Mon. Wea. Rev., 141, 283-306, https://doi.org/10.1175/MWR-D-11-00201.1.

Hay, L. E., and M. Clark, 2003: Use of statistically and dynamically downscaled atmospheric model output for hydrologic simulations in three mountainous basins in the western United
States. J. Hydrol., 282, 56-75, https://doi.org/10.1016/S00221694(03)00252-X.

Hayhoe, K., and Coauthors, 2004: Emissions pathways, climate change, and impacts on California. Proc. Natl. Acad. Sci. USA, 101, 12 422-12 427, https://doi.org/10.1073/pnas.0404500101.

Heikkilä, U., A. Sandvik, and A. Sorteberg, 2011: Dynamical downscaling of ERA-40 in complex terrain using the WRF regional climate model. Climate Dyn., 37, 1551-1564, https:// doi.org/10.1007/s00382-010-0928-6.

Heinzeller, D., M. Duda, and H. Kunstmann, 2016: Towards convection-resolving, global atmospheric simulations with the Model for Prediction Across Scales (MPAS) v3.1: An extreme scaling experiment. Geosci. Model Dev., 9, 77-110, https:// doi.org/10.5194/gmd-9-77-2016.

Henn, B., A. J. Newman, B. Livneh, C. Daly, and J. D. Lundquist, 2018: An assessment of differences in gridded precipitation datasets in complex terrain. J. Hydrol., 556, 1205-1219, https:// doi.org/10.1016/j.jhydrol.2017.03.008.

Huang, X., and P. A. Ullrich, 2016: Irrigation impacts on California's climate with the variable-resolution CESM. J. Adv. Model. Earth Syst., 8, 1151-1163, https://doi.org/ 10.1002/2016MS000656.

—, and — 2017: The changing character of twenty-firstcentury precipitation over the western United States in the variable-resolution CESM. J. Climate, 30, 7555-7575, https:// doi.org/10.1175/JCLI-D-16-0673.1.

— A. M. Rhoades, P. A. Ullrich, and C. M. Zarzycki, 2016: An evaluation of the variable resolution-CESM for modeling California's climate. J. Adv. Model. Earth Syst., 8, 345-369, https://doi.org/10.1002/2015MS000559.

Hurrell, J. W., J. J. Hack, D. Shea, J. M. Caron, and J. Rosinski, 2008: A new sea surface temperature and sea ice boundary dataset for the Community Atmosphere Model. J. Climate, 21, 5145-5153, https://doi.org/10.1175/2008JCLI2292.1.

, and Coauthors, 2013: The Community Earth System Model: A framework for collaborative research. Bull. Amer. Meteor. Soc., 94, 1339-1360, https://doi.org/10.1175/BAMS-D-12-00121.1.

Iacono, M. J., J. S. Delamere, E. J. Mlawer, M. W. Shephard, S. A. Clough, and W. D. Collins, 2008: Radiative forcing by longlived greenhouse gases: Calculations with the AER radiative transfer models. J. Geophys. Res., 113, D13103, https://doi.org/ 10.1029/2008JD009944.

Jiménez, P. A., J. Dudhia, J. F. González-Rouco, J. Navarro, J. P. Montávez, and E. García-Bustamante, 2012: A revised scheme for the WRF surface layer formulation. Mon. Wea. Rev., 140, 898-918, https://doi.org/10.1175/MWR-D-11-00056.1.

Jin, J., and L. Wen, 2012: Evaluation of snowmelt simulation in the Weather Research and Forecasting Model. J. Geophys. Res., 117, D10110, https://doi.org/10.1029/2011JD016980.

Kanamaru, H., and M. Kanamitsu, 2008: Model diagnosis of nighttime minimum temperature warming during summer due to irrigation in the California Central Valley. J. Hydrometeor., 9, 1061-1072, https://doi.org/10.1175/2008JHM967.1.

Katragkou, E., and Coauthors, 2015: Regional climate hindcast simulations within Euro-CORDEX: Evaluation of a WRF multi-physics ensemble. Geosci. Model Dev., 8, 603-618, https://doi.org/10.5194/gmd-8-603-2015.

Lenihan, J. M., R. Drapek, D. Bachelet, and R. P. Neilson, 2003: Climate change effects on vegetation distribution, carbon, and fire in California. Ecol. Appl., 13, 1667-1681, https://doi.org/ $10.1890 / 025295$.

Leung, L. R., and Y. Qian, 2009: Atmospheric rivers induced heavy precipitation and flooding in the western U.S. simulated by the 
WRF regional climate model. Geophys. Res. Lett., 36, L03820, https://doi.org/10.1029/2008GL036445.

Liou, K., Y. Gu, L. Leung, W. Lee, and R. Fovell, 2013: A WRF simulation of the impact of 3-D radiative transfer on surface hydrology over the Rocky Mountains and Sierra Nevada. Atmos. Chem. Phys., 13, 11 709-11721, https://doi.org/ 10.5194/acp-13-11709-2013.

Liu, C., and Coauthors, 2017: Continental-scale convectionpermitting modeling of the current and future climate of North America. Climate Dyn., 49, 71-95, https://doi.org/ 10.1007/s00382-016-3327-9.

Lo, M.-H., and J. S. Famiglietti, 2013: Irrigation in California's Central Valley strengthens the southwestern U.S. water cycle. Geophys. Res. Lett., 40, 301-306, https://doi.org/ 10.1002/grl.50108.

Mahmood, R., S. A. Foster, T. Keeling, K. G. Hubbard, C. Carlson, and R. Leeper, 2006: Impacts of irrigation on 20th century temperature in the northern Great Plains. Global Planet. Change, 54, 1-18, https://doi.org/10.1016/j.gloplacha.2005.10.004.

Margulis, S. A., G. Cortés, M. Girotto, and M. Durand, 2016a: A Landsat-era Sierra Nevada snow reanalysis (1985-2015). J. Hydrometeor., 17, 1203-1221, https://doi.org/10.1175/JHMD-15-0177.1.

,,-- L. S. Huning, D. Li, and M. Durand, 2016b: Characterizing the extreme 2015 snowpack deficit in the Sierra Nevada (USA) and the implications for drought recovery. Geophys. Res. Lett., 43, 6341-6349, https://doi.org/10.1002/ 2016GL068520.

Mearns, L. O., W. Gutowski, R. Jones, R. Leung, S. McGinnis, A. Nunes, and Y. Qian, 2009: A regional climate change assessment program for North America. Eos, Trans. Amer. Geophys. Union, 90, 311, https://doi.org/10.1029/2009EO360002.

Miller, N. L., K. Hayhoe, J. Jin, and M. Auffhammer, 2008: Climate, extreme heat, and electricity demand in California. J. Appl. Meteor. Climatol., 47, 1834-1844, https://doi.org/ 10.1175/2007JAMC1480.1.

Morrison, H., and A. Gettelman, 2008: A new two-moment bulk stratiform cloud microphysics scheme in the Community Atmosphere Model, version 3 (CAM3). Part I: Description and numerical tests. J. Climate, 21, 3642-3659, https://doi.org/ 10.1175/2008JCLI2105.1.

NCEP, 2000: NCEP FNL operational model global tropospheric analyses, continuing from July 1999. Research Data Archive at the National Center for Atmospheric Research, Computational and Information Systems Laboratory, accessed September 2017, https://doi.org/10.5065/D6M043C6.

Neale, R. B., and Coauthors, 2010: Description of the NCAR Community Atmosphere Model (CAM5.0). NCAR Tech. Note NCAR/TN-486+STR, 268 pp., www.cesm.ucar.edu/ models/cesm1.1/cam/docs/description/cam5_desc.pdf.

Oleson, K. W., and Coauthors, 2010: Technical description of version 4.0 of the Community Land Model (CLM). NCAR Tech. Note NCAR/TN-478+STR, 257 pp., https://doi.org/ 10.5065/D6FB50WZ.

Pavelsky, T. M., S. Kapnick, and A. Hall, 2011: Accumulation and melt dynamics of snowpack from a multiresolution regional climate model in the central Sierra Nevada, California. J. Geophys. Res., 116, D16115, https://doi.org/10.1029/ 2010JD015479.

_, S. Sobolowski, S. B. Kapnick, and J. B. Barnes, 2012: Changes in orographic precipitation patterns caused by a shift from snow to rain. Geophys. Res. Lett., 39, D16115, https://doi.org/ 10.1029/2012GL052741.
Pierce, D. W., and Coauthors, 2013a: The key role of heavy precipitation events in climate model disagreements of future annual precipitation changes in California. J. Climate, 26, 5879-5896, https://doi.org/10.1175/JCLI-D-12-00766.1.

_ changes in California temperature and precipitation using statistical and dynamical downscaling. Climate Dyn., 40, 839856, https://doi.org/10.1007/s00382-012-1337-9.

Qian, Y., W. I. Gustafson, L. R. Leung, and S. J. Ghan, 2009: Effects of soot-induced snow albedo change on snowpack and hydrological cycle in western United States based on Weather Research and Forecasting chemistry and regional climate simulations. J. Geophys. Res., 114, D03108, https://doi.org/ 10.1029/2008JD011039.

— S. J. Ghan, and L. R. Leung, 2010: Downscaling hydroclimatic changes over the western US based on CAM subgrid scheme and WRF regional climate simulations. Int. J. Climatol., 30, 675-693, https://doi.org/10.1002/joc.1928.

Raleigh, M. S., K. Rittger, C. E. Moore, B. Henn, J. A. Lutz, and J. D. Lundquist, 2013: Ground-based testing of MODIS fractional snow cover in subalpine meadows and forests of the Sierra Nevada. Remote Sens. Environ., 128, 44-57, https:// doi.org/10.1016/j.rse.2012.09.016.

Rhoades, A. M., X. Huang, P. A. Ullrich, and C. M. Zarzycki, 2016: Characterizing Sierra Nevada snowpack using variableresolution CESM. J. Appl. Meteor. Climatol., 55, 173-196, https://doi.org/10.1175/JAMC-D-15-0156.1.

— P. A. Ullrich, and C. M. Zarzycki, 2018a: Projecting 21st century snowpack trends in western USA mountains using variable-resolution CESM. Climate Dyn., 50, 261-288, https:// doi.org/10.1007/s00382-017-3606-0.

,,,--- H. Johansen, S. A. Margulis, H. Morrison, Z. Xu, and W. Collins, 2018b: Sensitivity of mountain hydroclimate simulations in variable-resolution CESM to microphysics and horizontal resolution. J. Adv. Model. Earth Syst., 10, 13571380, https://doi.org/10.1029/2018MS001326.

Skamarock, W. C., J. B. Klemp, J. Dudhia, D. O. Gill, D. M. Barker, W. Wang, and J. G. Powers, 2005: A description of the Advanced Research WRF version 2. NCAR Tech. Note NCAR/ TN-468+STR, 88 pp., https://doi.org/10.5065/D6DZ069T.

Sorooshian, S., J. Li, K.-1. Hsu, and X. Gao, 2011: How significant is the impact of irrigation on the local hydroclimate in California's Central Valley? Comparison of model results with ground and remote-sensing data. J. Geophys. Res., 116, D06102, https://doi.org/10.1029/2010JD014775.

Subin, Z., W. Riley, J. Jin, D. Christianson, M. Torn, and L. Kueppers, 2011: Ecosystem feedbacks to climate change in California: Development, testing, and analysis using a coupled regional atmosphere and land surface model (WRF3-CLM3.5). Earth Interact., 15, https://doi.org/10.1175/2010EI331.1.

Sun, F., A. Hall, M. Schwartz, D. B. Walton, and N. Berg, 2016: Twenty-first-century snowfall and snowpack changes over the Southern California mountains. J. Climate, 29, 91-110, https:// doi.org/10.1175/JCLI-D-15-0199.1.

Ullrich, P., 2014: SQuadGen: Spherical Quadrilateral Grid Generator. UC Davis, http://climate.ucdavis.edu/squadgen.php.

Urrutia, R., and M. Vuille, 2009: Climate change projections for the tropical Andes using a regional climate model: Temperature and precipitation simulations for the end of the 21st century. J. Geophys. Res., 114, D02108, https://doi.org/10.1029/2008JD011021.

Van der Linden, P., and J. Mitchell, Eds., 2009: ENSEMBLES: Climate change and its impacts: Summary of research and results from the ENSEMBLES project. ENSEMBLES Rep., 
Met Office Hadley Centre, 160 pp., http://ensembles-eu. metoffice.com/docs/Ensembles_final_report_Nov09.pdf.

Wang, M., and P. Ullrich, 2018: Marine air penetration in California's Central Valley: Meteorological drivers and the impact of climate change. J. Appl. Meteor. Climatol., 57, 137154, https://doi.org/10.1175/JAMC-D-17-0089.1.

, — - and D. Millstein, 2018a: Datasets on hub-height wind speed comparisons for wind farms in California. Data Brief, 19, 214-221, https://doi.org/10.1016/j.dib.2018.05.031.

$\ldots, \ldots$, and ——, 2018b: The future of wind energy in California: Future projections with the variable-resolution CESM. Renewable Energy, 127, 242-257, https://doi.org/10.1016/ j.renene.2018.04.031.

Wilkinson, R., K. Clarke, M. Goodchild, J. Reichman, and J. Dozier, 2002: Preparing for a changing climate: The potential consequences of climate variability and change for California. California Regional Assessment Group Rep., 431 pp., http://www.ncgia.ucsb.edu/pubs/CA_Report.pdf.

Wise, E. K., 2012: Hydroclimatology of the US Intermountain West. Prog. Phys. Geogr., 36, 458-479, https://doi.org/10.1177/ 0309133312446538.
Wu, C., X. Liu, Z. Lin, A. M. Rhoades, P. A. Ullrich, C. M. Zarzycki, Z. Lu, and S. R. Rahimi-Esfarjani, 2017: Exploring a variable-resolution approach for simulating regional climate in the Rocky Mountain region using the VR-CESM. J. Geophys. Res. Atmos., 122, 10 939-10 965, https://doi.org/ 10.1002/2017JD027008.

Zarzycki, C. M., C. Jablonowski, and M. A. Taylor, 2014a: Using variable resolution meshes to model tropical cyclones in the Community Atmosphere Model. Mon. Wea. Rev., 142, 12211239, https://doi.org/10.1175/MWR-D-13-00179.1.

—, M. N. Levy, C. Jablonowski, J. R. Overfelt, M. A. Taylor, and P. A. Ullrich, 2014b: Aquaplanet experiments using CAM's variable-resolution dynamical core. J. Climate, 27, 5481-5503, https://doi.org/10.1175/JCLI-D-14-00004.1.

— C. Jablonowski, D. R. Thatcher, and M. A. Taylor, 2015: Effects of localized grid refinement on the general circulation and climatology in the Community Atmosphere Model. J. Climate, 28, 2777-2803, https://doi.org/10.1175/JCLI-D-14-00599.1.

Zhang, G. J., and N. A. McFarlane, 1995: Role of convective scale momentum transport in climate simulation. J. Geophys. Res., 100, 1417-1426, https://doi.org/10.1029/94JD02519. 